\title{
mau \\ Fatigue Behavior of Smart Composites with Distributed Fiber Optic Sensors for Offshore Applications
}

\author{
Monssef Drissi-Habti *(D) and Venkadesh Raman \\ COSYS Department, Université Gustave Eiffel, IFSTTAR, F-77447 Marne-la-Vallée, France; \\ venkadesh.raman@ifsttar.fr \\ * Correspondence: monssef.drissi-habti@univ-eiffel.fr
}

check for updates

Citation: Drissi-Habti, M.; Raman, V. Fatigue Behavior of Smart Composites with Distributed Fiber Optic Sensors for Offshore

Applications. J. Compos. Sci. 2022, 6, 2 https://doi.org/10.3390/jcs6010002

Academic Editor:

Francesco Tornabene

Received: 25 November 2021

Accepted: 20 December 2021

Published: 22 December 2021

Publisher's Note: MDPI stays neutral with regard to jurisdictional claims in published maps and institutional affiliations.

Copyright: (C) 2021 by the authors. Licensee MDPI, Basel, Switzerland. This article is an open access article distributed under the terms and conditions of the Creative Commons Attribution (CC BY) license (https:// creativecommons.org/licenses/by/ $4.0 /)$.

\begin{abstract}
Continuous inspection of critical zones is essential to monitor the state of strain within offshore wind blades, thus, enabling appropriate actions to be taken when needed to avoid heavy maintenance. Wind-turbine blades contain various substructures made of composites, sandwich panel, and bond-joined parts that need reliable Structural Health Monitoring (SHM) techniques. Embedded, distributed Fiber-Optic Sensors (FOS) are one of the most promising techniques that are commonly used for large-scale smart composite structures. They are chosen as monitoring systems for their small size, being noise-free, and low electrical risk characteristics. In recent works, we have shown that embedded FOSs can be positioned linearly and/or in whatever position with the scope of providing pieces of information about actual strain in specific locations. However, linear positioning of distributed FOS fails to provide all strain parameters, whereas sinusoidal sensor positioning has been shown to overcome this issue. This method can provide multiparameter strains over the whole area when the sensor is embedded. Nevertheless, and beyond what a sensor can offer as valuable information, the fact remains that it is a "flaw" from the perspective of mechanics and materials. In this article and through some mechanical tests on smart composites, evidence was given that the presence of embedded FOS influences the mechanical behavior of smart composites, whether for quasi-static or fatigue tests, under 3-point bending. Some issues directly related to the fiber-architecture have to be solved.
\end{abstract}

Keywords: Structural Health Monitoring (SHM); fatigue; Fiber Optic Sensors (FOS); smart composite; embedded sensor; numerical simulation; Finite Element Analysis (FEA); resin-eye pocket

\section{Introduction}

In applications such as offshore wind turbines, structures are subjected to harsh environments and variations in temperature during the operating period. Accordingly, they expect maintenance and verification processes in a certain interval of time. Within EVEREST Project, previous research have shown that smart composites can be appropriate structural materials for future wind turbines with length beyond $100 \mathrm{~m} \mathrm{[1-4].} \mathrm{Maintenance} \mathrm{works} \mathrm{of}$ these structures are conducted by nondestructive testing (NDT) in most of the times [1]. Material development demands modern NDT equipment and qualified manpower, which increases the maintenance process cost. Structural Health Monitoring (SHM) techniques can prevent heavy maintenance by monitoring structures under harsh environments remotely. The sensors are used to provide the information about intrinsic material properties [2]. Fiber optic sensors (FOSs) were proved as a reliable choice for SHM of composites from previous studies [3,4]. They have a high confidence level to sense the microscale strains in composites. Embedding FOS into a structure is an important issue, since the interface between FOS and surrounding material has to allow accurate measurements. One must admit that FOSs are foreign entities to the host structure; therefore, they may have some influence on the stress and strain field in the vicinity of the material [5-7]. One of the major issues relating to the insertion of FOS is to be sure that they can continue to emit precise and reliable signals regardless of the weather and the intensity of the gusts of winds of changing 
directions that the offshore farm will see during exploitation. It is this very precise point that is the focus of this article through an introductory study of the fatigue behavior of intelligent composites. It is easily understandable that meaningful embedding FOS is linked to two parameters: fiber-optic diameter and the type of fiber-optic coating. Indeed, the core diameter is preferred to be small in order to keep the sensibility higher [8]. Standard FOSs are available at 125 to 250 microns-diameter in cross-section. While embedding this small sensor in between the composite plies, the resin makes a deposit around the FOSs, because the composite plies are as thin as the FOSs. This resin deposit makes a lenticular resin pocket in the composite material, as mentioned in Figure 1. This resin eye will vary the intrusive property of FOS towards the host material, as it changes the stress-strain transfer of the structure in a microscale level. In addition, the resin pocket may initiate delamination cracks in the composite, as it arises between two composite plies. The dimension of the resin eye is variable depending on the FOS's diameter. The sensor with large diameter makes more resin concentration, which affects the material properties. The disadvantages inherent to embedding optical fiber sensors within composite structures are counterbalanced by their very valuable functions as sensors. Indeed, FOSs are basically classified based on measurement techniques. Unlike traditional sensors that measure at predetermined points, a distributed FOS has a capability of sensing throughout fiber length [9,10]. Distributed sensors have an advantage of providing strain and temperature variations in a single FOS line. The main disadvantage is that their interrogator system is expensive and not effective for small structures [11]; therefore, distributed sensors are mostly used in a long civil structure [12]. However, the introduction of advanced technology for low distance sensing (High spatial resolution) lets distributed sensors detect strain in small structures (specimen level) [13].

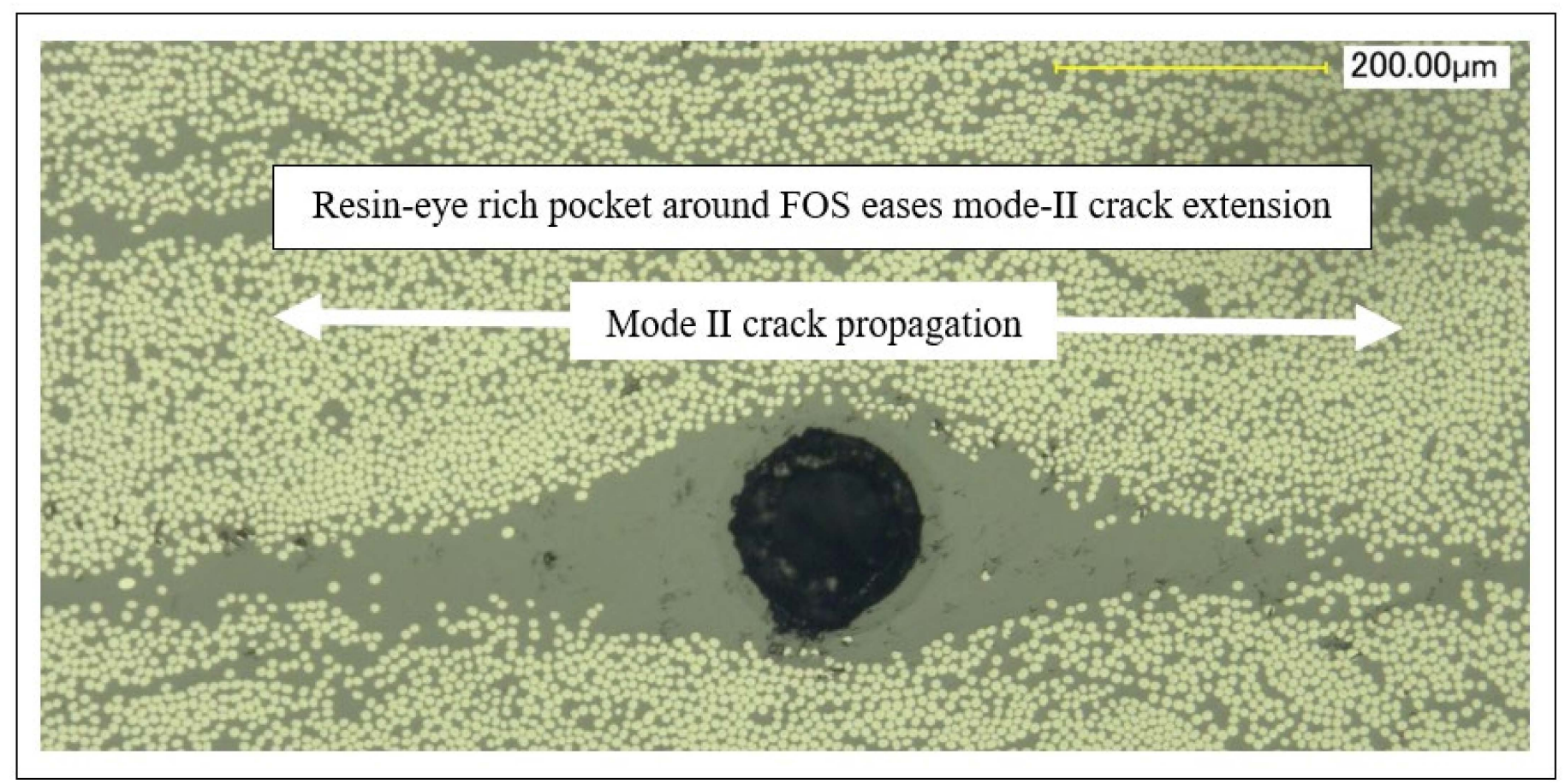

Figure 1. Resin-eye rich concentrations around FOS. The bigger is FO diameter, the more facilitated is mode-II delamina-tion crack initiation and extension.

Another point of great importance is related to placement of sensors within composites and bond joints. Two main solutions have been imagined and finely simulated elsewhere [1-4]; namely, placing FOS straight parallel to bonded joints and a placement where a sinusoidal fiber is covering the largest part of bond joint surfaces and/or plies (Figure 2). As the bond joints are wide, many parallel FOS are needed for fine monitoring and this is particularly costly since many optical back-scattering apparatuses, OBRs, are 
needed. The alternative sinusoidal placement strategy on a single FOS embedded with a well-mastered periodicity that will ease monitoring throughout the joints and composite interplies was shown to be more suitable. It is noteworthy that strain values close to the edge were simulated so as to avoid FOS slippage and sensibility reduction. Finally, our research work highlighted the advantages of sinusoidal placement for large-scale wind-blades [1-4].

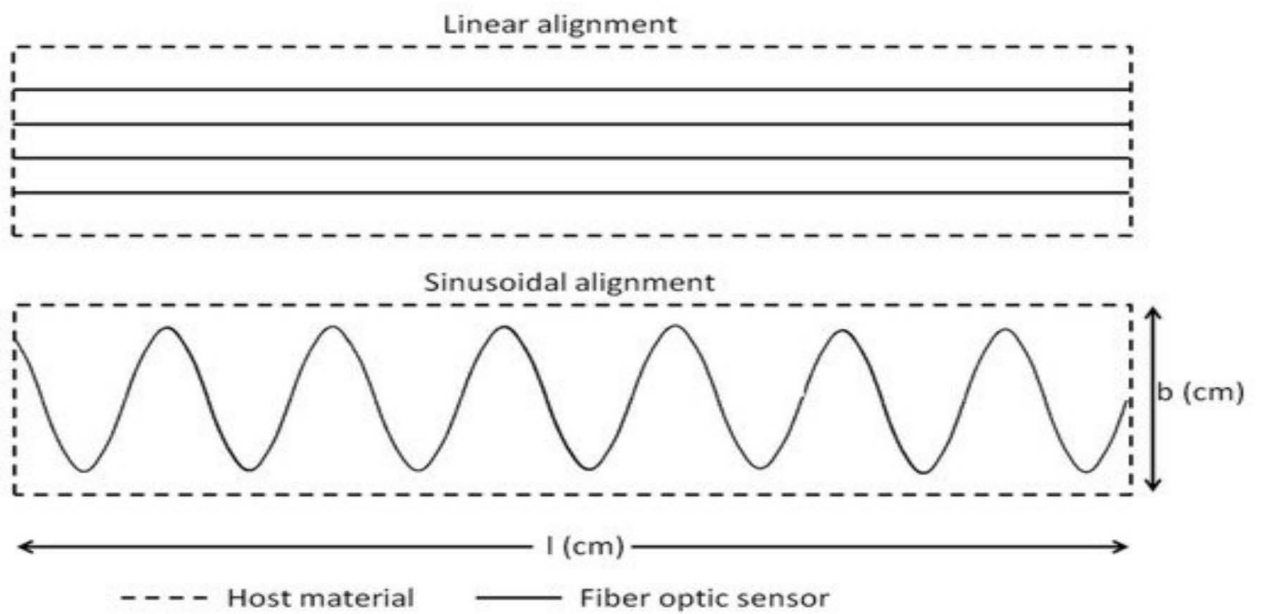

Figure 2. Illustration of straight and sinusoidal Fiber FOS placement strategies [1-4].

Previous works [1-4] also emphasized that straight FOS placement is of some interest for SHM of large wind turbine blades; one of its main drawback is the impossibility of measuring multiparameter strains, alongside the difficulty in identifying strain coordinates, especially when loading direction is random, which is typically the case of offshore farms (Figure 3).

(a)

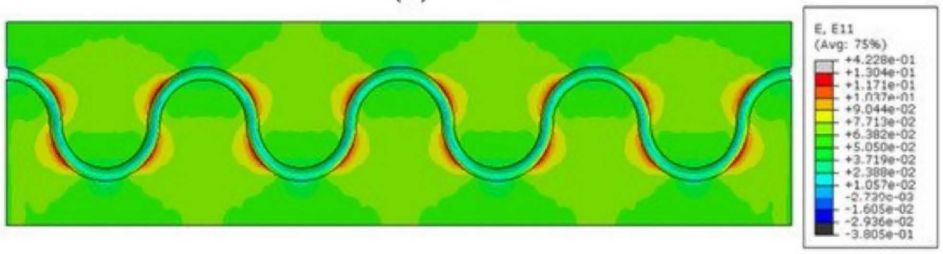

(b)

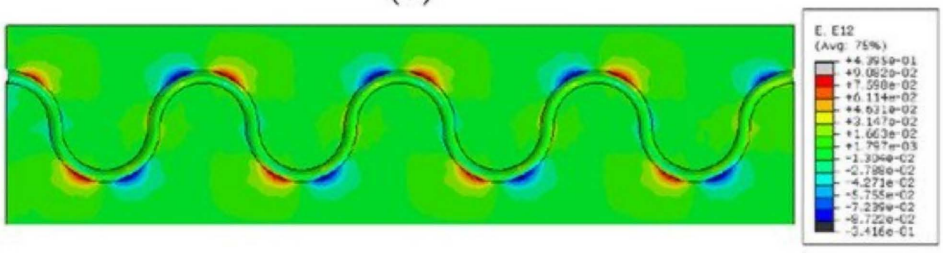

(c)

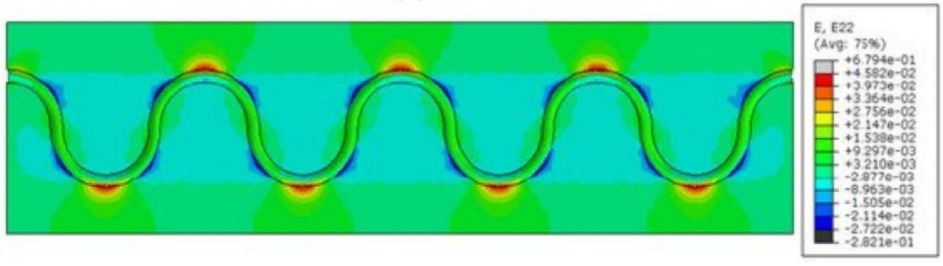

Figure 3. (a) $\mathrm{E}_{11}$ strain component; (b) $\mathrm{E}_{12}$ strain component; (c) $\mathrm{E}_{22}$ strain component (acrylate-coated FOS numerical model; the value observed in the host epoxy), sinusoidal alignment. Multiparameter strains are clearly visible in sinusoidal placement. Straight placement shows lateral strains only while sinusoidally placed FOS shows strain in linear, shear, and lateral directions. 
More recently, dual-sinusoidal FOSs' placement (Figure 4) was shown to be a more promising strategy as it can provide strain signals in longitudinal as well as in lateral directions, thus, easing monitoring bending and torsion loadings simultaneously. This adds to the fact that dual-sinusoidal placement allows for a maximum surface coverage of the area to be monitored. As a summary, the critical point that should be kept in mind is the possibility of using distributed FOS in a large spectrum of structures of various dimensions and shapes in various industries. For these sensors to give the full measure of their physical means without turning out to be "flaws", their sizes should be as miniaturized as possible and they should be placed far enough from edges so as to prevent the composite from delamination. Finally, the placement of sensors must be designed and technologically chosen to ease up the fineness of measurements.

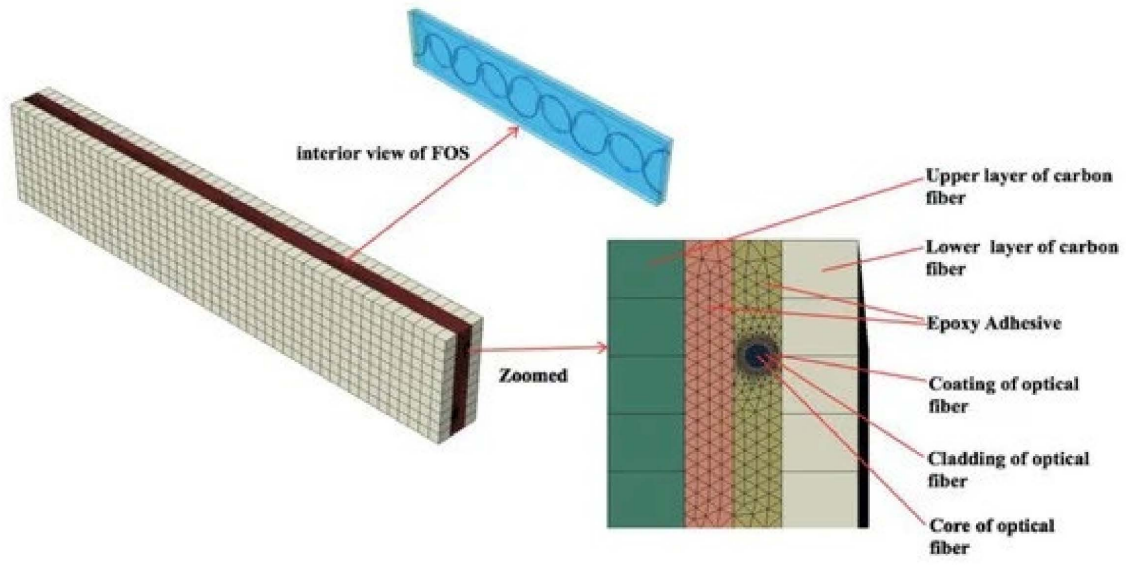

(a)

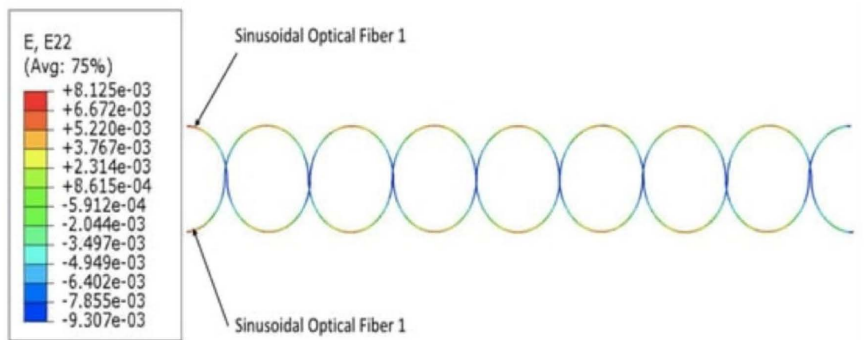

(b)

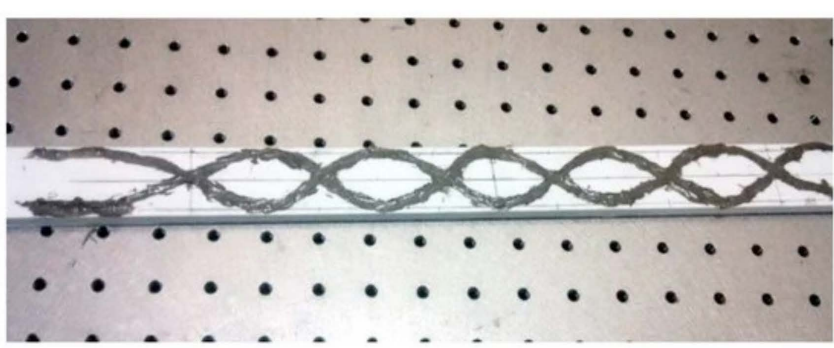

(c)

Figure 4. (a) Loads and boundary conditions properties used for model having dual-sinusoidal optical fiber placement. (b) Dual-sinusoidal FOSs' placement embedded on a glass composite specimen. (c) Strain measurements showing dual-sinusoidal FOSs placement (placement in dual-sinusoidal mode, in phase opposition, provides coverage complementary to that of a single sinusoidal fiber).

In current article, the capacity of distributed FOS to monitor strain under fatigue loading is studied. The target here was not to conduct a full campaign of fatigue, but rather, to obtain a preliminary appraisal of actual capabilities of the smart composite, especially, how damage qualitatively proceeds when smart composites are loaded under fatigue through a comparison between specimens with and without FOS, and how FOS accommodates mechanical loading while continuing to send meaningful signals. A comparison was conducted between FOS and MTS mechanical sensors; throughout the experiments, due to the slight difference in strain measurement resulting from the fact that FOS is recording the strain at the location where it is embedded, within tensile surface of the flexured specimens, FOS will naturally indicate a lower strain than the one recorded by MTS mechanical sensor, which is bonded at the external part of tensile surface.

Some additional fatigue tests were conducted up to $10^{6}$ cycles to validate the sensor functionality at a high number of cycles. The scope is also to show that embedding sensors 
is far from being a straightforward technology and that some fiber-architectures not subject to easy-delamination are the best candidates to "host" FOS.

\section{Experiments}

\subsection{Specimen Preparation and Instrumentation}

The composite was manufactured by prepreg method using a matrix volume fraction of $34 \%$ and volume fraction of fibers of $66 \%$. HexPly M79/34\%/UD300/CHS type laminates were considered. UD stands for unidirectional plies and ' 34 ' stands for percentage of resin concentration. The materials are fully in-line with wind-turbine manufacturing standards. The material properties are shown in Table 1.

Table 1. Properties of the materials used in the article [1].

\begin{tabular}{cccc}
\hline Materials & Density $\left(\mathbf{k g} / \mathbf{m}^{\mathbf{3}}\right)$ & Modulus $\mathbf{( M P a})$ & Poisson's Ratio \\
\hline Composite (CFRP) & 1950 & $\mathrm{E}_{1}=103,000$ & 0.05 \\
& & $\mathrm{E}_{2}=10,400$ & \\
FOS Acrylate coating & 950 & $\mathrm{G}_{12}=54,000$ & 0.35 \\
Silica Glass & 2400 & 2700 & 0.17 \\
\hline
\end{tabular}

The composite plates were made by 'Autoclave vacuum-bag' method. Individual sheets of prepreg material were laid-up and placed in an open mold. The material was covered with release film, bleeder/breather material, and a vacuum bag (Figure 5). CFRP prepreg laminates were spread on a work table.

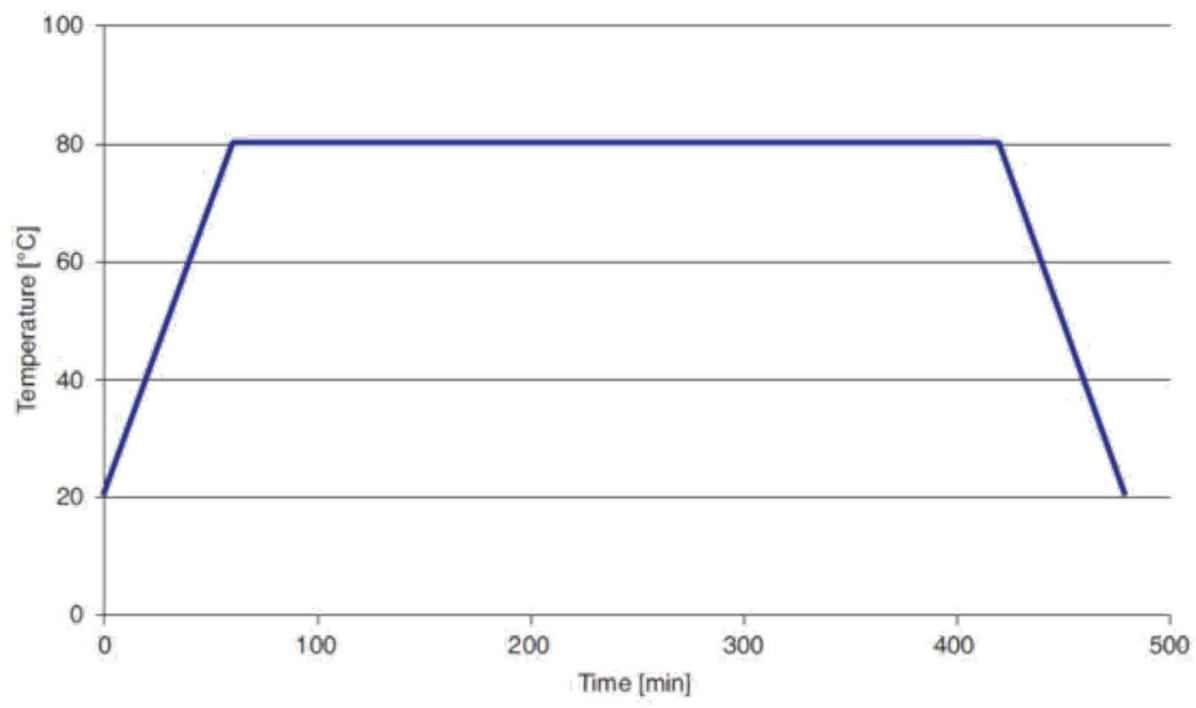

Figure 5. Polymerization cycle for composite specimen fabrication.

Twelve plies and the top layer were covered by 'breather cloth' to ensure uniform vacuum pressure across the component, and the 'caul plate' protected the bottom layer to define the second surface. For unidirectional composite (UD) specimens, all laminates were oriented towards $0^{\circ}$ of coordinate system of specimen. So, laminates were arranged in a $\left[0^{\circ}\right]_{6 \mathrm{~S}}$ format. For angle-ply specimens, the laminates were oriented at $[ \pm 45]_{3 s}$. A vacuum pressure was applied on part and the entire mold was placed into an autoclave (heated pressure vessel) [13-15]. The part was cured with a continuous vacuum to extract entrapped gases from laminate. It affords precise control during the molding process. The polymerization cycle worked on $80^{\circ} \mathrm{C}$ for $360 \mathrm{~min}$ (Figure 5). After curing, the specimen plate was removed. This final product was reduced to specimen dimensions described by ASTM D790 standard [16] (Figure 6). Specimen length of $200 \mathrm{~mm}$, width of $20 \mathrm{~mm}$, and thickness of $3.5 \mathrm{~mm}$ were considered. 


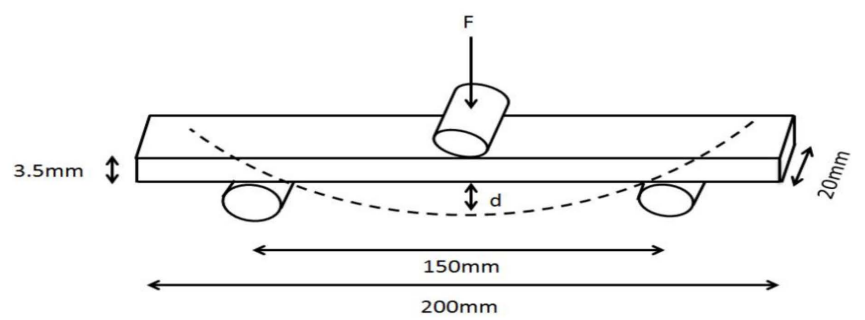

(a)

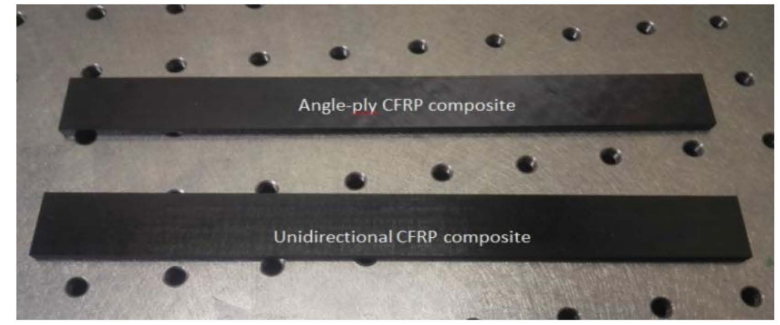

(b)

Figure 6. (a) Three-point bending specimen dimensions and loading condition; (b) UD and Angle-ply specimens.

There are several ways to embedded sensors in composite laminates. We used a hand-layup and aligning method. The FOS with $125-\mu \mathrm{m}$ outer diameter and acrylate coating is cut down according to the work plate dimensions. The specimen dimensions were noted initially on work-plane. The sensor was aligned exactly at the midpoint of the specimen, lengthwise. Therefore, FOS is parallel to the fiber's orientation in UD laminates and oriented $45^{\circ}$ in angle-ply laminates. The FOS should not be placed in the neutral axis of the specimen stacking, because of strain neutralization under bending load [17]. So, to collect the appropriate strain information of composite material, FOS was placed between the 2nd and 3rd (from tensile side of specimen-bottom side) layers of the specimen lay-up stacking. Once the FOS was placed in a specific position, it was checked for straightness to avoid sensor waviness. Thereafter, the remaining plies were stacked-up and the fabrication process continues similarly to the known procedure. After the curing process, FOS connectors were connected to the excess FOS that comes out of the plate. The FC/PC connector was used in our work, see Figure 7. The specimens were polished and verified by ultrasonic method to detect the presence of flaws prior to testing. In this work, source specimen represents specimen without sensor and smart specimen represents specimen with sensors. In addition, we considered only distributed FOS and assumed that distributed sensors are suitable to collect the strain for long distance with less error.

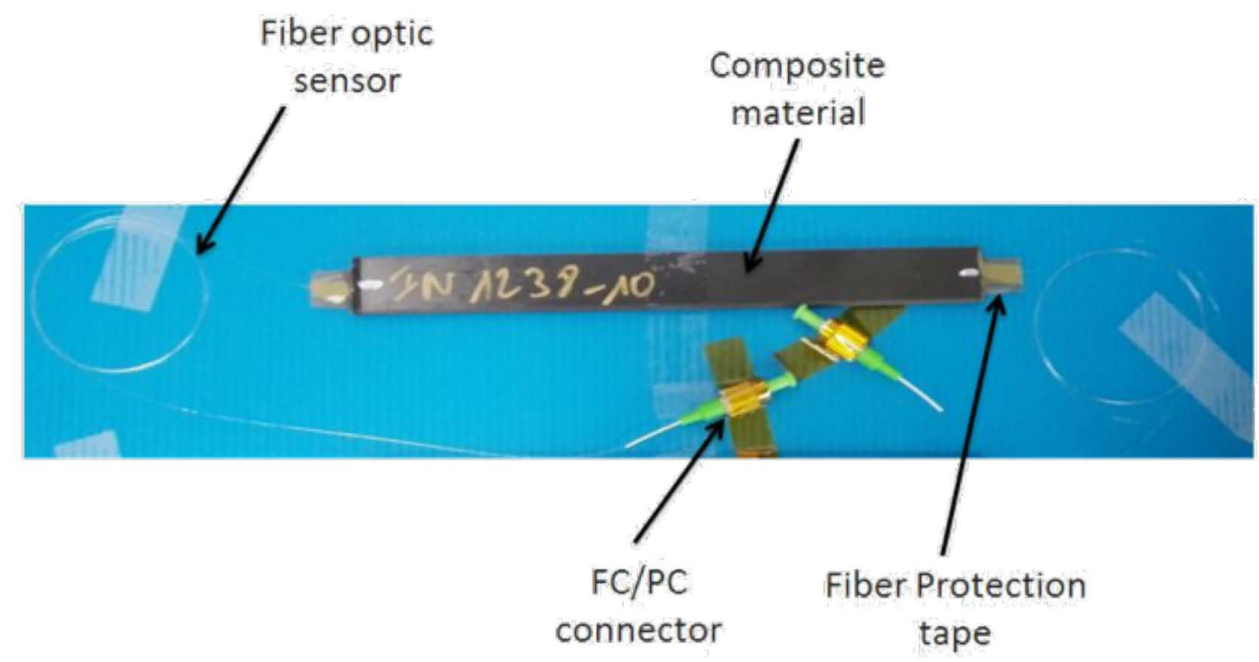

Figure 7. CFRP composite specimen with embedded FOS and connectors.

The sensors that are considered are Rayleigh ones [18,19]. The mentioned method operates by reflectometer. Rayleigh scattering is interrogated by LUNA 4600 OBR equipment. The spatial resolution defines the quality of strain values; it is $1 \mathrm{~mm}$ for Luna $4600 \mathrm{OBR}$. In addition, by using spot scan method, we can go up to $3 \mathrm{~Hz}$ of strain acquisition speed. The sensor coverage length is $2 \mathrm{~km}$ [13]. 


\subsection{Experimental Setup}

The mechanical experiment was carried out on MTS 100-kN hydraulic testing machine. All experiments were maintained at room temperature $\left(23^{\circ} \mathrm{C}\right)$. The temperature of testing space was controlled by a climate chamber with an effective air-conditioning system. Bending test set-up is shown in Figure 8. Roller supports were used, where the distance between outer spans were maintained at $150 \mathrm{~mm}$ for all experiments. Specimens were placed at the midsection of the roller to distribute the stress equally over their width. The two bottom rollers were fixed to a mobile actuator and the top roller was connected with the fixed frame. The load was applied in the middle of the specimen by raising the bottom rollers (displacement measurement). The force transducer was connected to the top roller. The displacement was measured from the mobile actuator's translation. The mechanical component was controlled by testsuite ${ }^{\mathrm{TM}} \mathrm{TW}$ software. Before every experiment, the software was controlled for error and proper calibration. The bending test was performed under quasi-static, load-unload, and fatigue modes. The specimen was placed on bottom rollers and the fiber optic connectors were fixed to LUNA OBR inlet port, ensuring special care to specimen edges to avoid FOS failure. Figure 9 shows the final experimental setup. In the results section, quasi-static and load-unload experiment results are shown initially. Afterwards, the specimens are observed by numerical microscope for microdamage evaluation. Next, the LNCF (Low Number of Fatigue Cycles) experiment results are demonstrated. The mechanical property (stiffness) between source and smart specimen is compared. Thereafter, stiffness and sensor's strain are compared in smart specimens. Later, HNCF (High Number of Cycles Fatigue) experiment results are shown to check the sensors functionality.

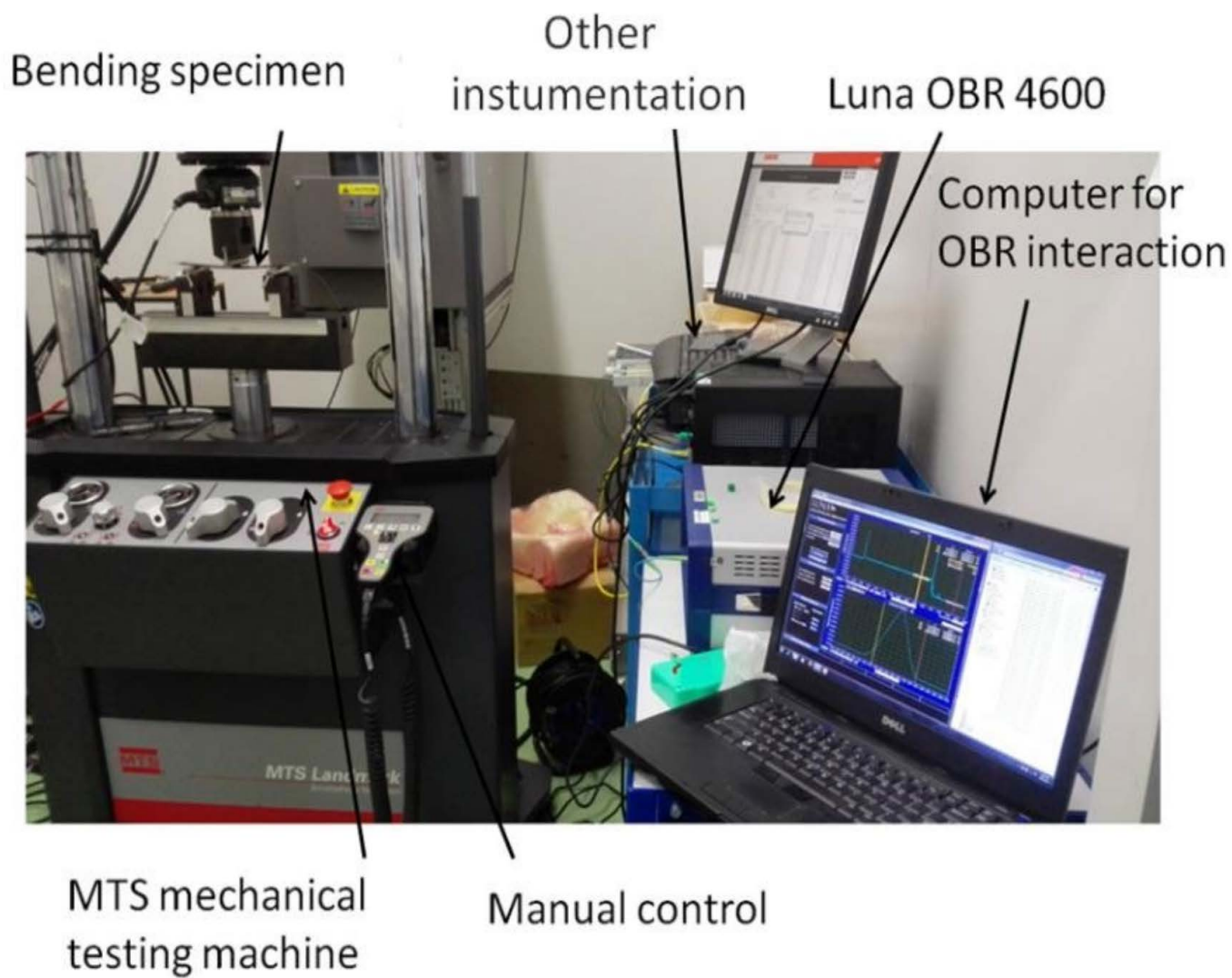

Figure 8. Bending experiment final setup. 


\section{Bending test curve}

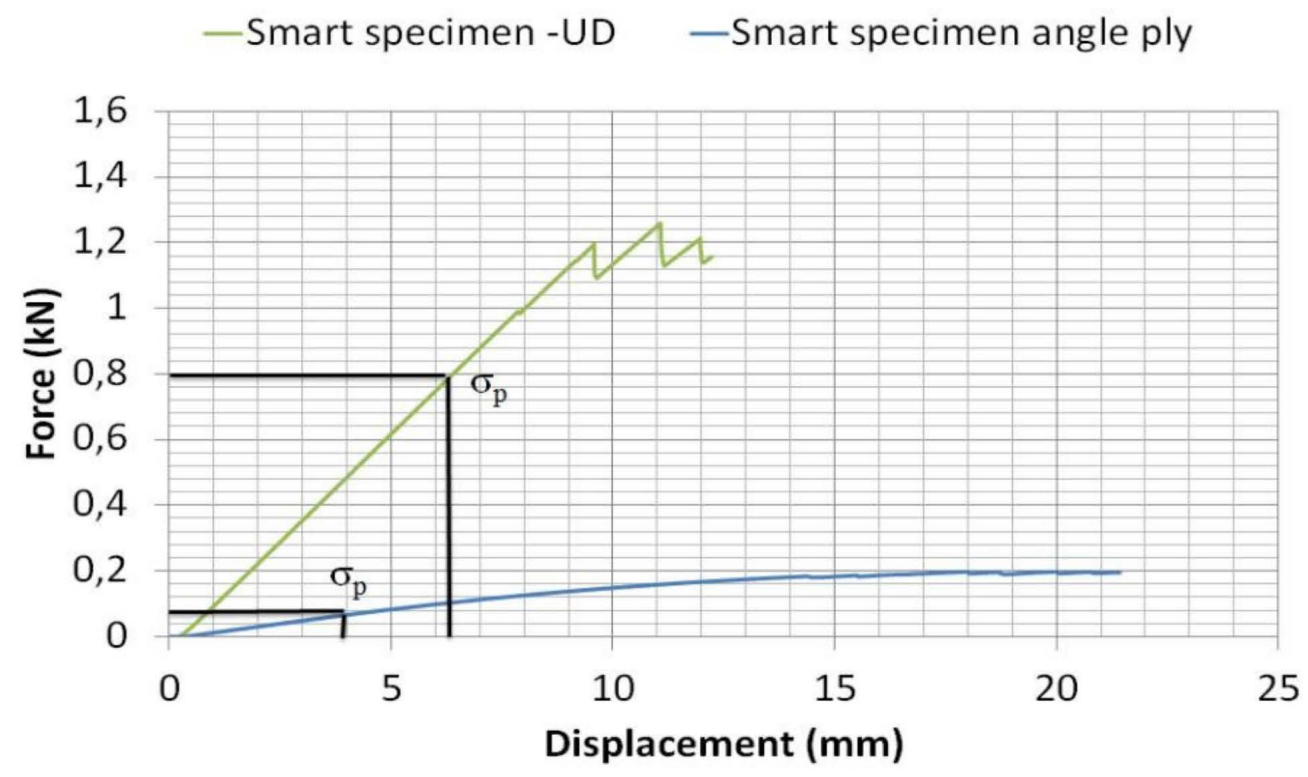

Figure 9. Quasi-static experiment result for CFRP specimen under 3-point bending.

\section{Results}

\subsection{Quasi-Static Test}

Mechanical tests were force-controlled; the rate of applied force was $0.1 \mathrm{kN} / \mathrm{min}$, as per ASTM D790 standard [16]. The mechanical behavior of CFRP specimens under quasi-static bending load is shown in Figure 9.

The Young's modulus calculated (from the slope of curves [20]) for UD CFRP composite is higher than the one of angle-ply CFRP specimen [21]. The method described by Christiansen et al. was used to calculate the material properties under bending load. It is difficult to see the difference in material properties between source and smart specimens under quasi-static loading. The calculated material properties are shown in Table 2 and will be used in the fatigue loading stress definition.

Table 2. Mechanical properties of UD and angle-ply CFRP specimens with FOS.

\begin{tabular}{ccc}
\hline Properties & UD with Sensor & 45 with Sensor \\
\hline Flexural modulus & $109 \mathrm{GPa}$ & $17.4 \mathrm{GPa}$ \\
Maximum stress & $1557 \mathrm{MPa}$ & $259.5 \mathrm{MPa}$ \\
Proportional limit & $(0.80 \mathrm{GPa}, 0.0069)$ & $(0.08 \mathrm{GPa}, 0.0050)$ \\
\hline
\end{tabular}

\subsection{Load-Unload Tests}

The load-unload experiment was conducted with imposed displacement in step-bystep regime. The mechanical behavior of load-unload test on UD and angle-ply composites are illustrated in Figures 10 and 11, respectively. The following equations have been used to calculate mechanical properties, where $\mathrm{F}$ is the load at the fracture point, $\mathrm{L}$ is the length between outer spans, $b$ is the width of a specimen, $d$ is the thickness of a specimen, $E$ is the Young's modulus, and $\mathrm{I}$ is the area moment of inertia.

$$
\begin{gathered}
\text { Flexural stress }=\sigma_{\text {flexural }}=3 \mathrm{FL} / 2 \mathrm{bd}^{2} \\
\text { Flexural strain }=\varepsilon=6 \delta \mathrm{d} / \mathrm{L}^{2} \\
\text { Maximum deflection }=\delta=\mathrm{FL}^{3} / 48 \mathrm{EI} \\
\text { Flexural modulus }=\mathrm{FL}^{3} / 4 \mathrm{bd}^{3} \delta
\end{gathered}
$$




\section{Load-unload unidirectional specimen}

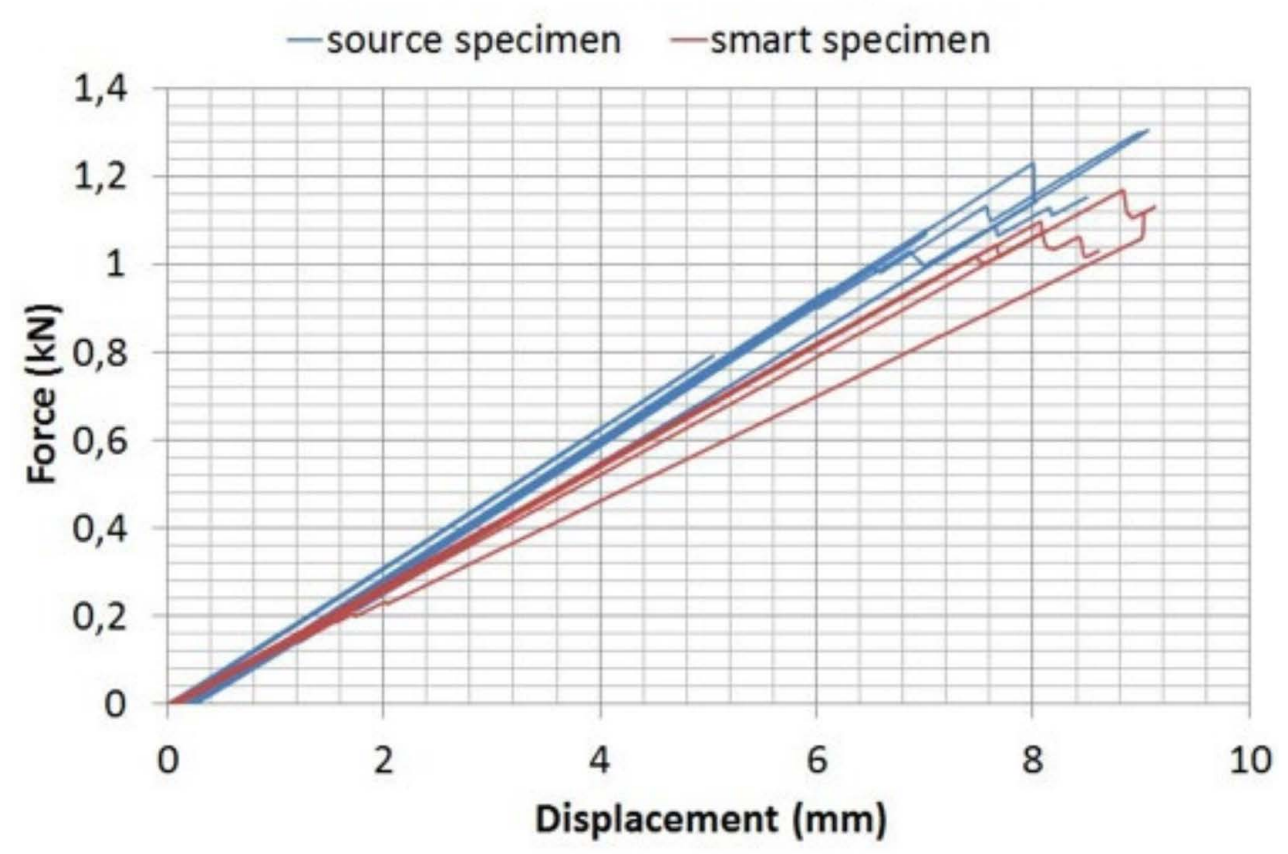

Figure 10. Force-displacement curve of unidirectional specimens under load-unload condition.

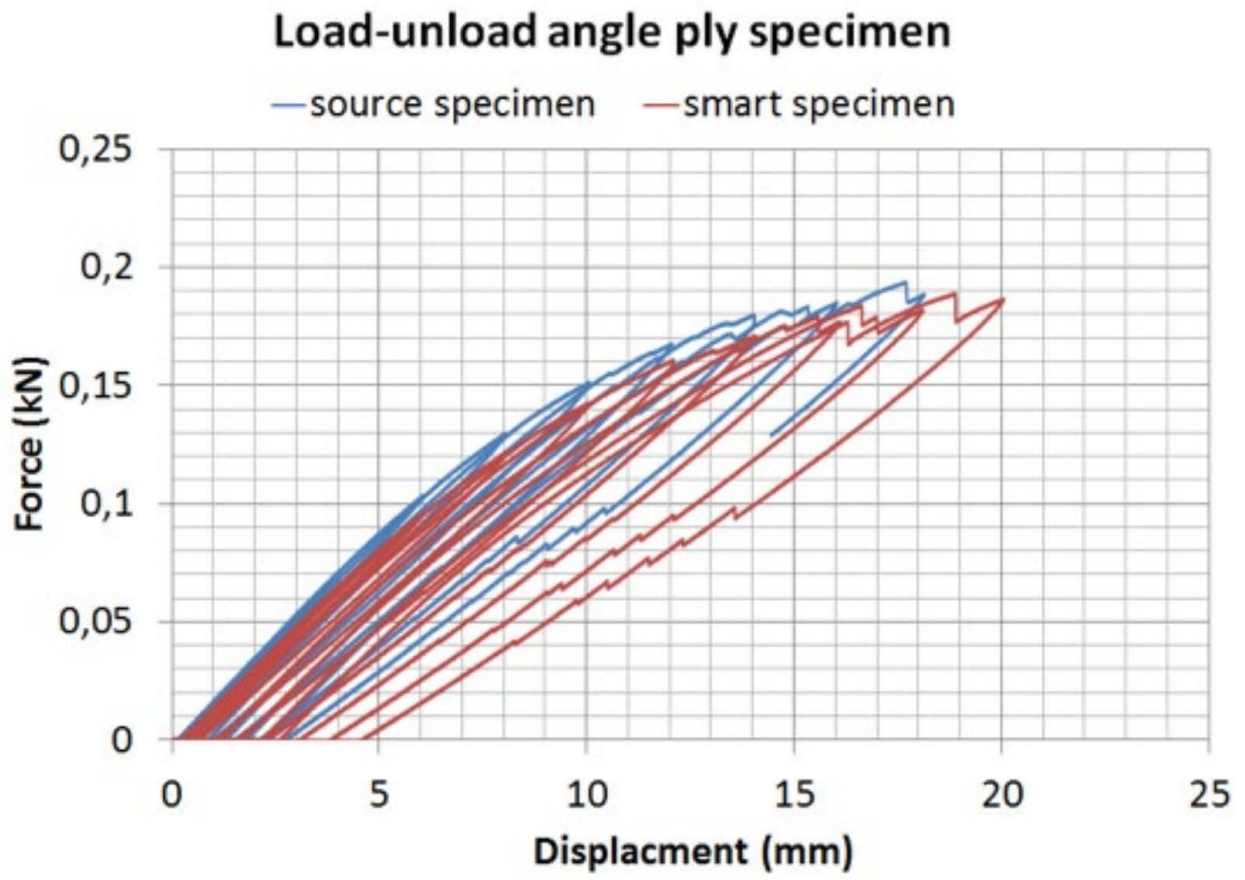

Figure 11. Force-displacement curve of angle-ply specimens under load-unload condition.

In UD specimens, nonlinearity is not visible in the initial cycles, but situation is changing on further sequences. In addition, smart specimen's curve falls lower than the source specimen's curve, it shows that the presence of FOS affects somewhat the mechanical properties of smart composites. In the source composite, nonlinear behavior arises because of matrix damage that was revealed through microscopy observations (Figure 10). On smart composite, nonlinear behavior was expressed because of an accumulation of microdamage in matrix and resin concentration around FOS encapsulation.

Unlike UD composites, nonlinear behavior is clearly recognizable when loading/unloading angle-ply specimens with a tendency that starts very early (Figure 11). 
Matrix microcracking as well as failure of weakest fibers and their fragmentation are responsible for this behavior [22]. The nonlinear strain value is larger for specimens with embedded sensors. It is also worth noting that the overall curve slope is lower in the case of smart specimens and this tendency has been systematically shown, which indicates once again that embedded FOS brings some mechanical disturbance to the host material, as will be clearly shown further.

\subsubsection{Microscopy Analysis for Damage Assessment}

Figure 12 illustrates microdamage evolution in both UD and angle-ply specimens.

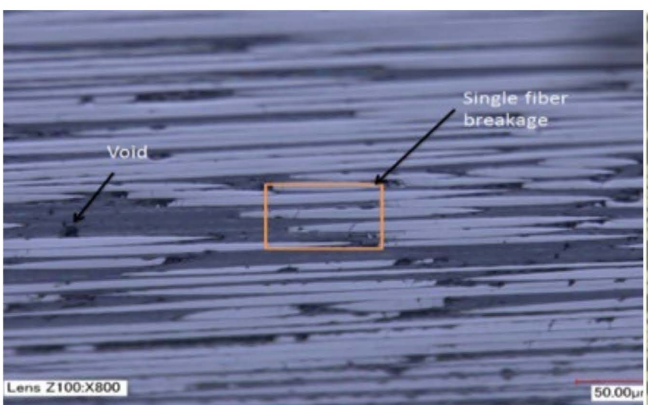

(a)

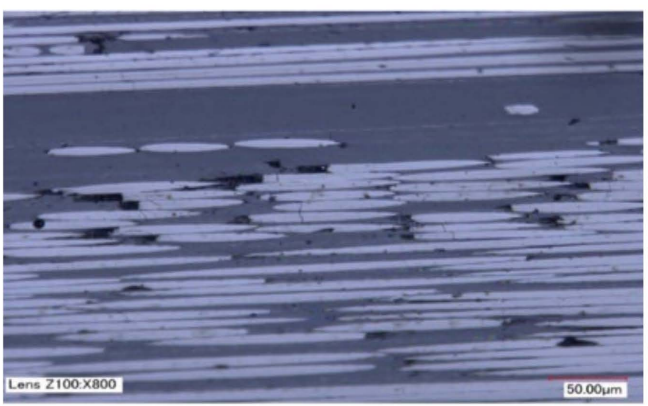

(b)

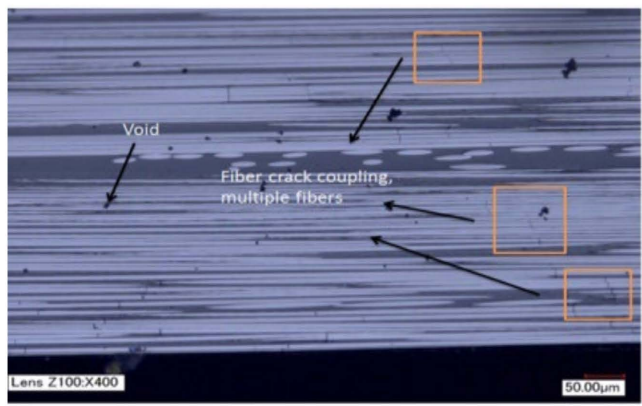

(c)

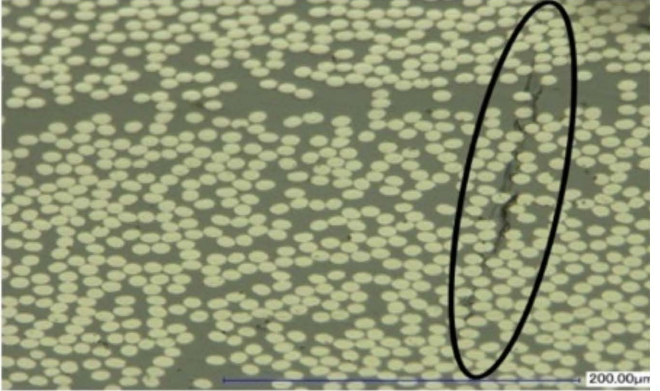

(d)

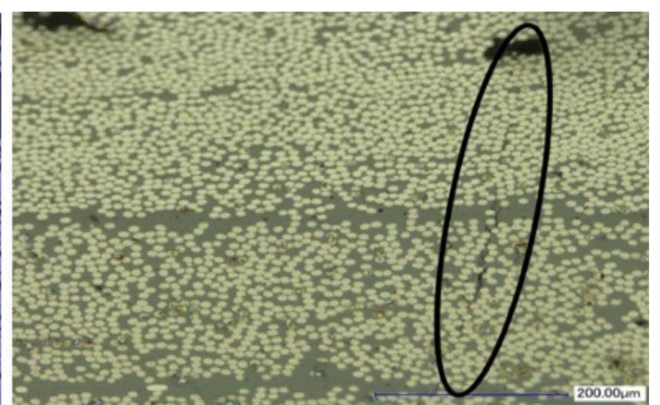

(e)

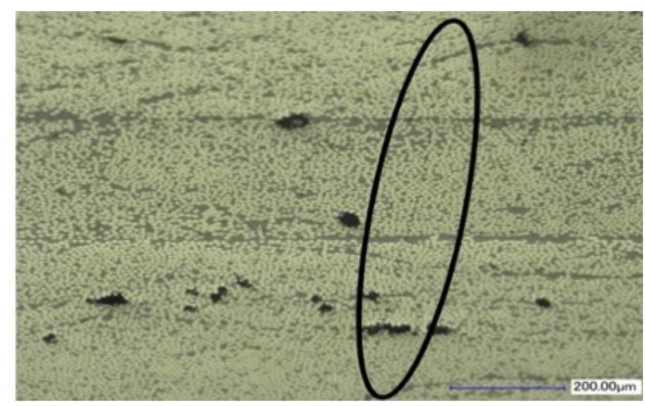

(f)

Figure 12. Micrographies of unidirectional specimen (a) at proportional limit, (b) at $0.9 \mathrm{kN}$, and (c) at $1.1 \mathrm{kN}$; angle-ply specimen (d) at proportional limit, (e) at $0.11 \mathrm{kN},(\mathbf{f})$ and at $0.14 \mathrm{kN}$ (microcracking extension).

At the early stage of loading, few matrix microcracks appear; as load increases, microcracks increase in length, followed by mode-II delamination. Matrix microcracking arose in various matrix areas as well as fiber-matrix debonding and weakest fibers failures [22-27]. It is important to note that big-resin-eye concentration around the sensors led to delamination, which is seemingly responsible for stiffness reduction (Figure 13). 


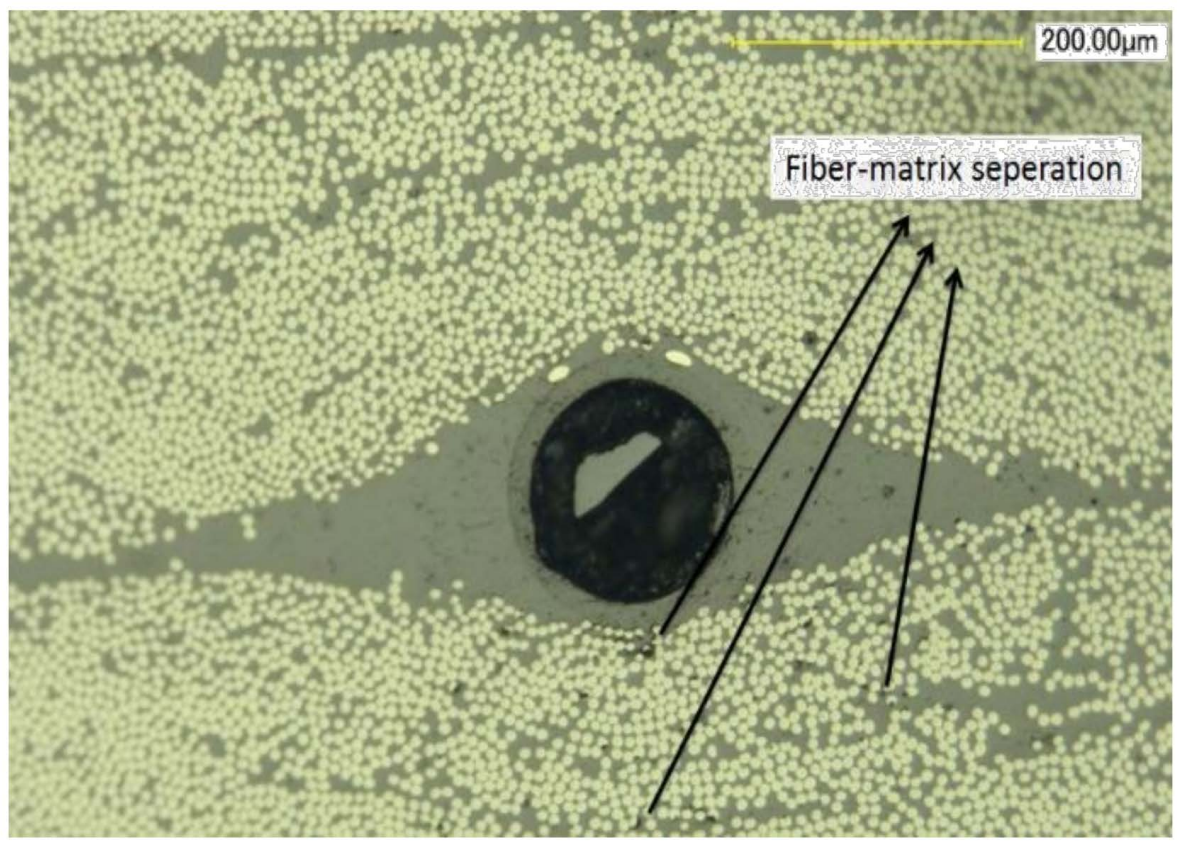

Figure 13. Micrography of damage on a UD specimen with FOS, postmortem.

\subsubsection{Comparison between Mechanically Recorded Strain and FOS Measurements}

Our focus is to check whether FOSs are able to deliver meaningful signals that can be continuously monitored up to the end of the experiment. Figure 14 shows load-unload test of UD smart specimens. The full slope of strain variation was finely recorded by embedded FOS, shown by the red color curve. The maximum strain detected by FOS in UD smart specimen is 4083 microstrain. The 3-D curve is plotted to show whether FOS is sticking to its original position without failure and/or sliding, which may come up with fatal errors. The 3-plot shows the bending profile of FOS signals during experiment (specific time). If FOS is broken uniquely in a specimen, signals will not appear in the FOS interface from broken location. In addition, if FOS slides inside composite plies, the location of curve will be shifted from its initial position $[17,28]$. Therefore, 3-D plot is a complimentary curve to confirm the performance of FOS.

Load-unload - unidirectional - Mechanical vs FO strain

-Mechanical strain

-FO strain

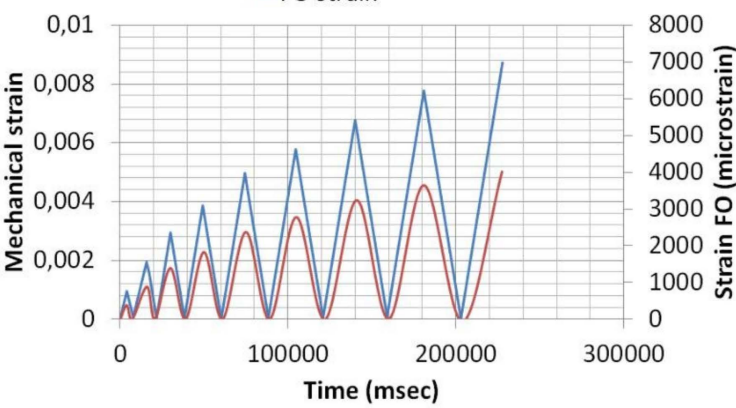

(a)

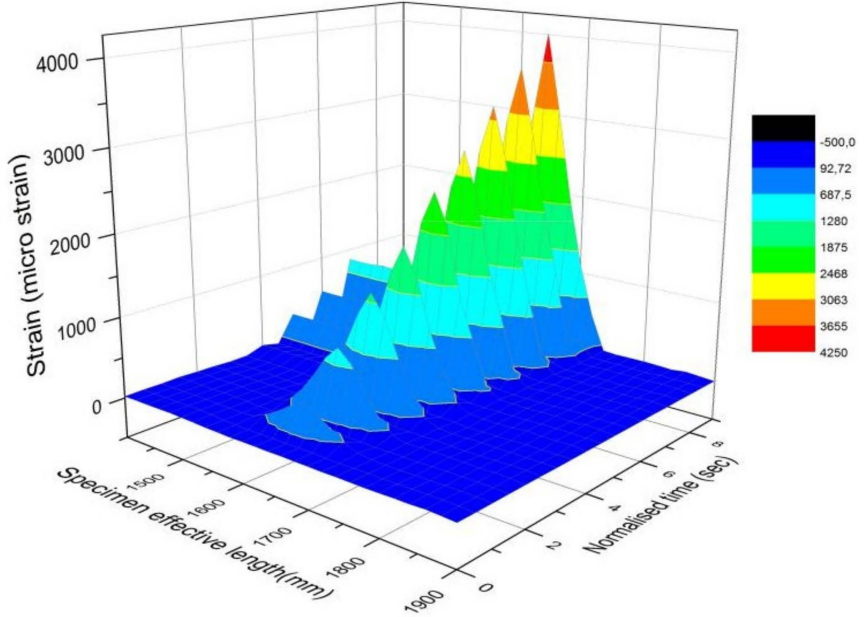

(b)

Figure 14. (a) Load-unload curve for smart UD specimen; (b) 3-D load-unload curve for smart UD specimen. 
In angle-ply specimens, FOS strain curve reflects the finely nonlinear behavior of smart composite. Nonlinear strain values are continuously increasing in each load-unload cycle, which is highlighted by circles in Figure 15. The mechanical strain does not show nonlinear behavior because tests were displacement-imposed. In both experiments, 3-D profile confirms the proper working of FOS.
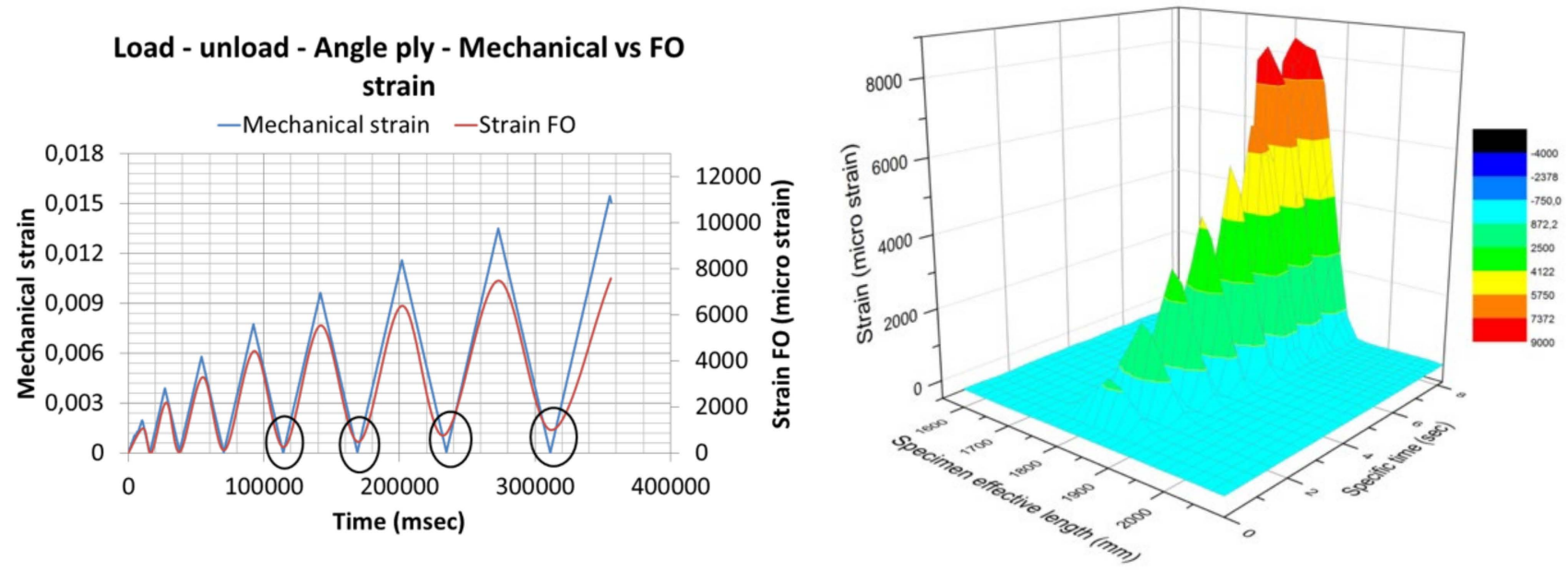

Figure 15. Load-unload test curve and 3D curve for smart angle-ply specimen.

The mechanical behavior under quasi-static loading came up with valuable pieces of information that helped us figure out how damage initiates and propagates in either standard and/or smart composites. It is therefore time to check more precisely how damage proceeds with repeated cycling and this has been investigated under a low number of fatigue cycles (LNFC) tests. It is worthwhile to note once again that the idea here was not to carry out a full campaign of fatigue, since the target was not yet of composite reliability. Fatigue stress values at which tests were conducted were chosen with regard to proportional stress limit $\left(\sigma_{\mathrm{p}}\right)$ determined by quasi-static curves. Accordingly, tests were carried-out at $60 \%, 80 \%$, and $100 \%$ of the proportional limit. By doing so, our focus is to investigate the area of mechanical behavior, where there is no damage and/or limited damage initiation and development, in a way, enabling us to assume that damage accumulation brings "minor" perturbation to the mechanical system considered, let us say with no variation in volume $[29,30]$. Therefore, fatigue tests with a low number of cycles (LNFC $=10^{4}$ cycles) on specimens with and without embedded sensors can allow us to make clear comparisons on the effects of sensors presence in parent materials. Besides, once the maximum stress at which there is no stiffness decreases, even after $10^{4}$ cycles were identified, an additional fatigue test over $10^{6}$ cycles (HNFC $=10^{6}$ cycles) was carried out to check whether the tendency is still the same after 1 million cycles. Our fatigue tests were conducted at a constant amplitude, which merely refers to the fact that the maximum $\left(S_{\max }\right)$ and minimum stresses $\left(\mathrm{S}_{\min }\right)$ are constant for each cycle [31,32]. The other factors were referred from ASTM standard D3479/D3479 M [31], i.e., $\mathrm{S}_{\max }$ or $\sigma_{\max }$-maximum stress; $\mathrm{S}_{\min }$ or $\sigma_{\min }-$ minimum stress.

$$
\begin{gathered}
\text { Mean stress }\left(\sigma_{\mathrm{m}}\right)=\left(\mathrm{S}_{\max }+\mathrm{S}_{\min }\right) / 2 \\
\text { Stress range }\left(\sigma_{\mathrm{r}}\right)=\mathrm{S}_{\max }-\mathrm{S}_{\min } \\
\text { Stress amplitude }\left(\sigma_{\mathrm{a}}\right)=\left(\mathrm{S}_{\max }-\mathrm{S}_{\min }\right) / 2 \\
\text { Stress ratio }(\mathrm{R})=\mathrm{S}_{\max } / \mathrm{S}_{\min }
\end{gathered}
$$




\subsection{Low Number of Fatigue Cycles (LNFC) Tests}

In our constant amplitude fatigue condition, the maximum stress $\left(\mathrm{S}_{\max }\right)$ applied was $60 \%, 80 \%$, and $100 \%$ of proportional limit $\left(\sigma_{p}\right)$. The equivalent force and displacement were calculated from these stress values and introduced in our testing machine software. A ratio $\mathrm{R}=0.1$ (tension-tension) type fatigue condition with $1 \mathrm{~Hz}$ frequency was used. This value was chosen based on offshore technology, which shows that wind frequency lies between 0.5 and $2 \mathrm{~Hz}$ [15]. To avoid specimen slippage, $\mathrm{S}_{\min }=10 \%$ of $\mathrm{S}_{\max }$ was calculated and applied to specimens prior to the experiments. The maximum stress was maintained constant in all fatigue cycles. So, if microdamage is generated, strain increases along with number of cycles, which will result in stiffness drop [25,33,34]. Stiffness change was normalized in our study.

\section{Normalized stiffness $=$ Actual stiffness $/$ initial stiffness}

Figure 16 shows the fatigue behavior at a load of $0.6 \sigma_{p}$ of specimens made of UD composite. Results are comparable for source composite (without embedded sensors) and smart composites. The curves display no stiffness reduction; accordingly, the presence of FOS clearly does not bring any loss of mechanical properties. When loading the specimens at $0.8 \sigma_{\mathrm{p}}$ maximum stress, stiffness loss is observed in the initial cycles (up to 5000 cycles); thereafter, steady-state regime is attained. FOS presence generates additional loss of mechanical properties as if it was a "flaw". Stiffness drop in smart composite is due to the presence of large resin eye concentration around the FOS that promotes matrix microdamage at low stress levels, as will be shown later. Once damage reaches a steadystate level (stiffness drop is too low), there is no further stiffness reduction (after 5000 cycles). The same tendency is shown when loading under fatigue at a maximum stress of $\sigma_{p}$, where a sharp decrease in stiffness up to 5000 cycles followed by a steady state up to $10^{4}$ cycles is observed. The presence of FOS (resin eye concentration) induces matrix microcracking, delamination, and failure of weakest fibers, which leads to stiffness reduction.

In the case of fatigue behavior of angle-ply source and smart composite specimens tested under $0.6 \sigma_{\mathrm{p}}$, there was a minor stiffness decrease observed in the first cycles. However, overall normalized stiffness values were maintained close to 1 for source and smart specimens. Therefore, FOS does not feature any loss of mechanical properties to host material at this stress value. In the test carried out at $0.8 \sigma_{p}$ load fatigue, stiffness drop was observed in the initial cycles (up to 4000 cycles). Thereafter, steady-state regime is attained. This behavior demonstrates that damage initiation took place at initial cycles and slowed down subsequently. After few cycles, damage initiation is stopped, so the specimen retains the same stiffness. The presence of FOS is clearly shown to come up with a visible intrusive effect on the test conducted at a maximum stress of $1 \sigma_{p}$. Up to 4000 cycles, stiffness drop is high for smart specimens and, afterwards, the curve reaches a steady state regime. Damage that starts and extends within matrix resin-eye concentration creates a stiffness reduction in the first cycles. Compared with UD specimens, the stiffness decrease of angle-ply specimens is high. The stiffness reduction falls by up to 0.91 normalized value.

\subsubsection{Comparison between Mechanically Recorded Strain and FOS Measurements}

The evolution of stiffness is plotted as a function of fatigue cycles (Figure 17a). In the secondary axis, we plotted the values of strain delivered by FOS as a function of the number of cycles as well. As a reminder, our focus is to check whether FOSs are able to deliver meaningful signals that can be continuously monitored until the end of fatigue tests. Additionally, FOS signals should be coherent with stiffness evolution as a function of fatigue cycles, this last point will be checked out through comparison with the mechanical displacement sensor delivered by MTS testing machine. In the case of quasi-static tests, the coherence between the two signals is clearly shown. As previously mentioned, the slight difference comes from the fact that FOSs are recording the strain at the location where FOS is embedded, within the tensile surface of the specimen loaded under bending, which 
naturally will indicate a lower strain than the one recorded by MTS mechanical sensor. Indeed, the positioning of the later sensor is at the exterior of the tensile surface of the same specimen, which corresponds to the area of maximum bending deformation.

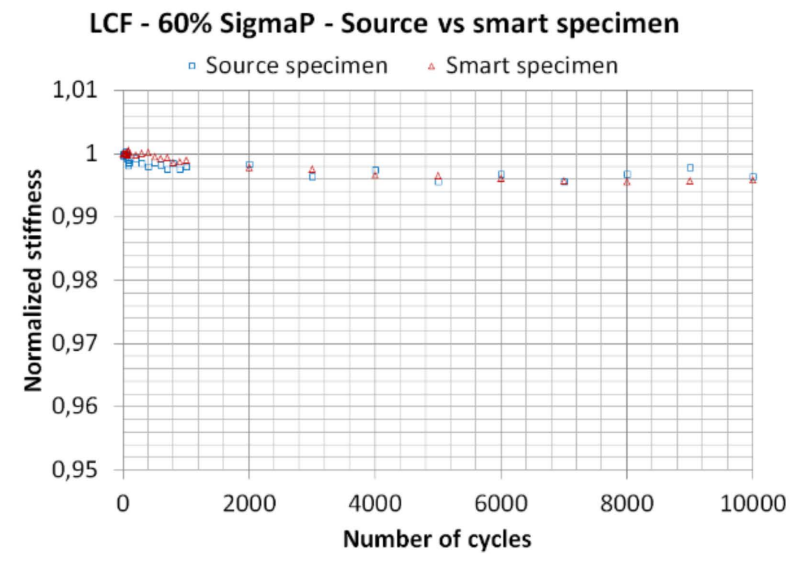

LCF - $\mathbf{8 0 \%}$ SigmaP - Source vs smart specimen

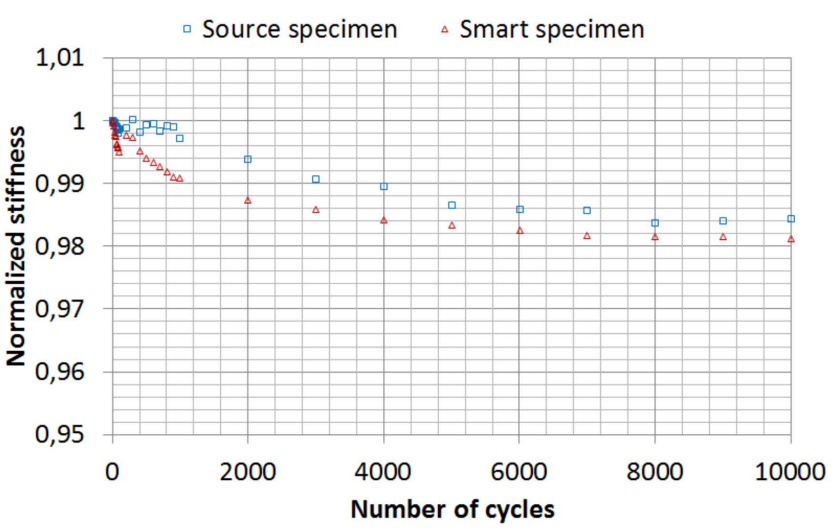

LCF - 100\% SigmaP - Source vs smart specimen

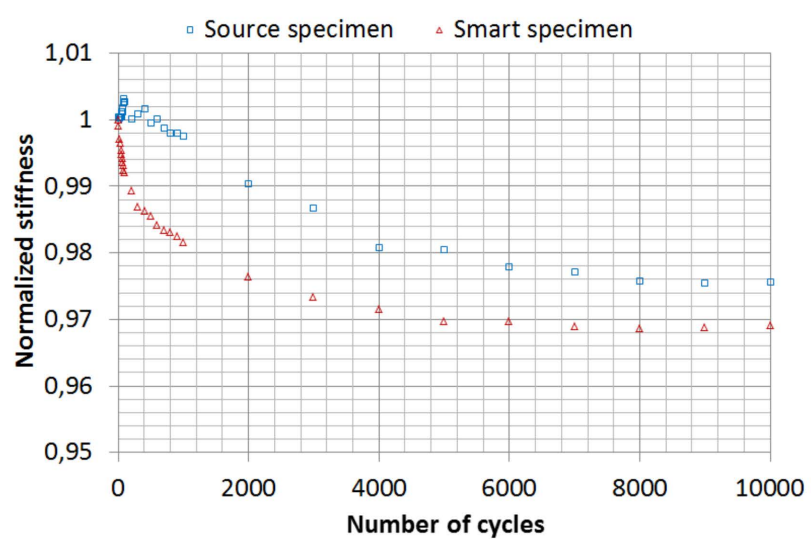

(a)
LCF - 60\% SigmaP - Source vs smart specimen

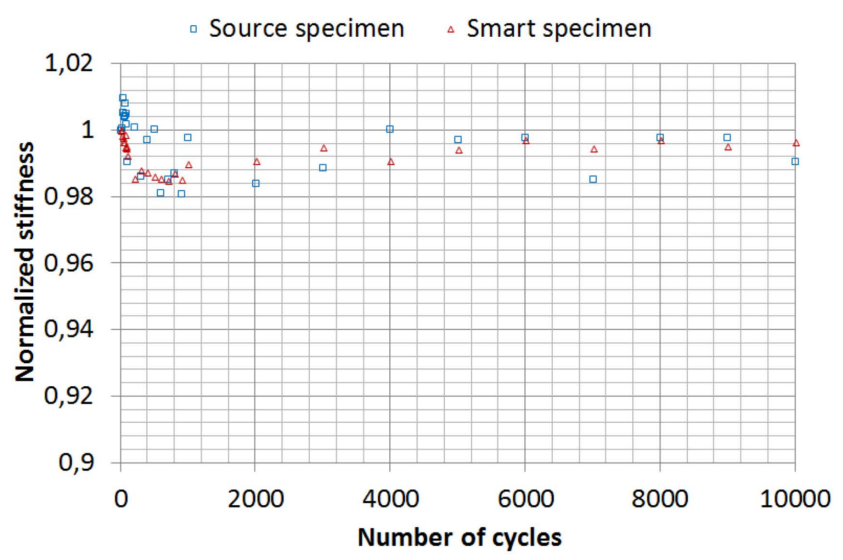

LCF - $\mathbf{8 0 \%}$ SigmaP - Source vs smart specimen

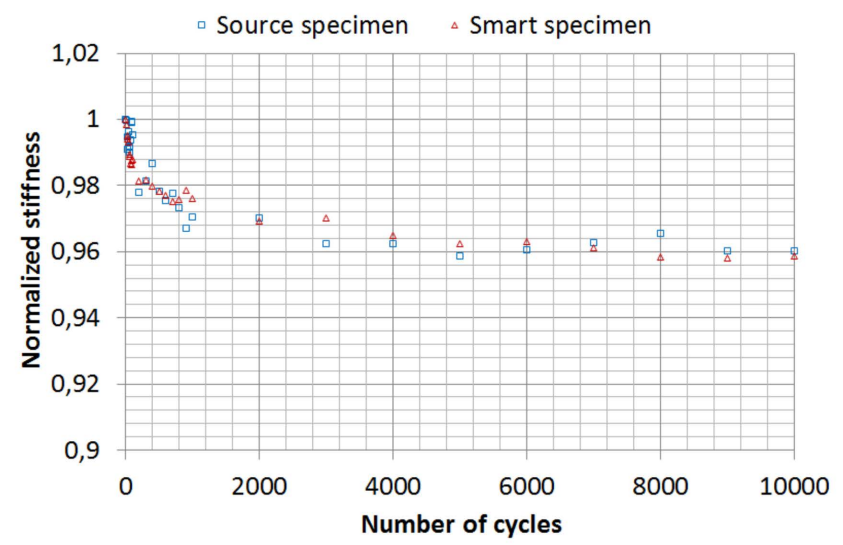

LCF - 100\% SigmaP - Source vs smart specimen

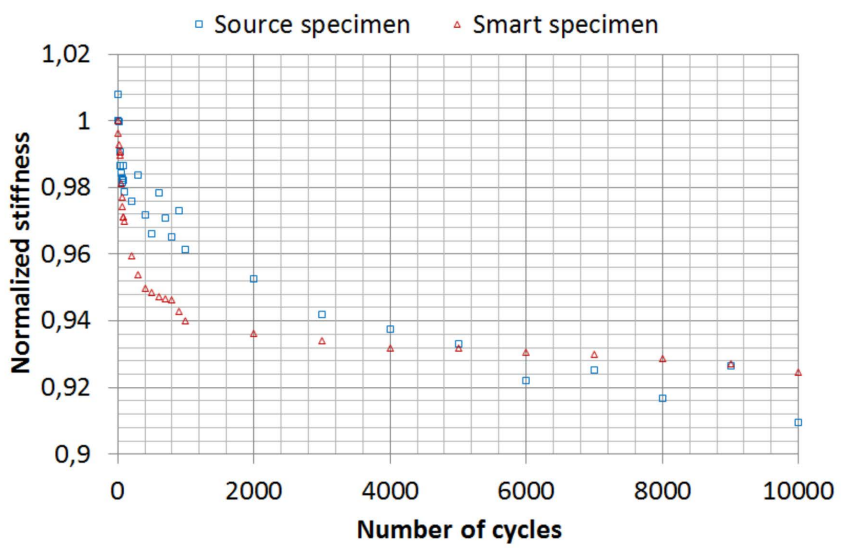

(b)

Figure 16. Source vs. smart UD and angle-ply specimen behavior under fatigue at $0.6 \sigma p, 0.8 \sigma p$, and 1.0 op. (a) Fatigue tests for UD specimens. (b) Fatigue tests for angle-ply specimens. 

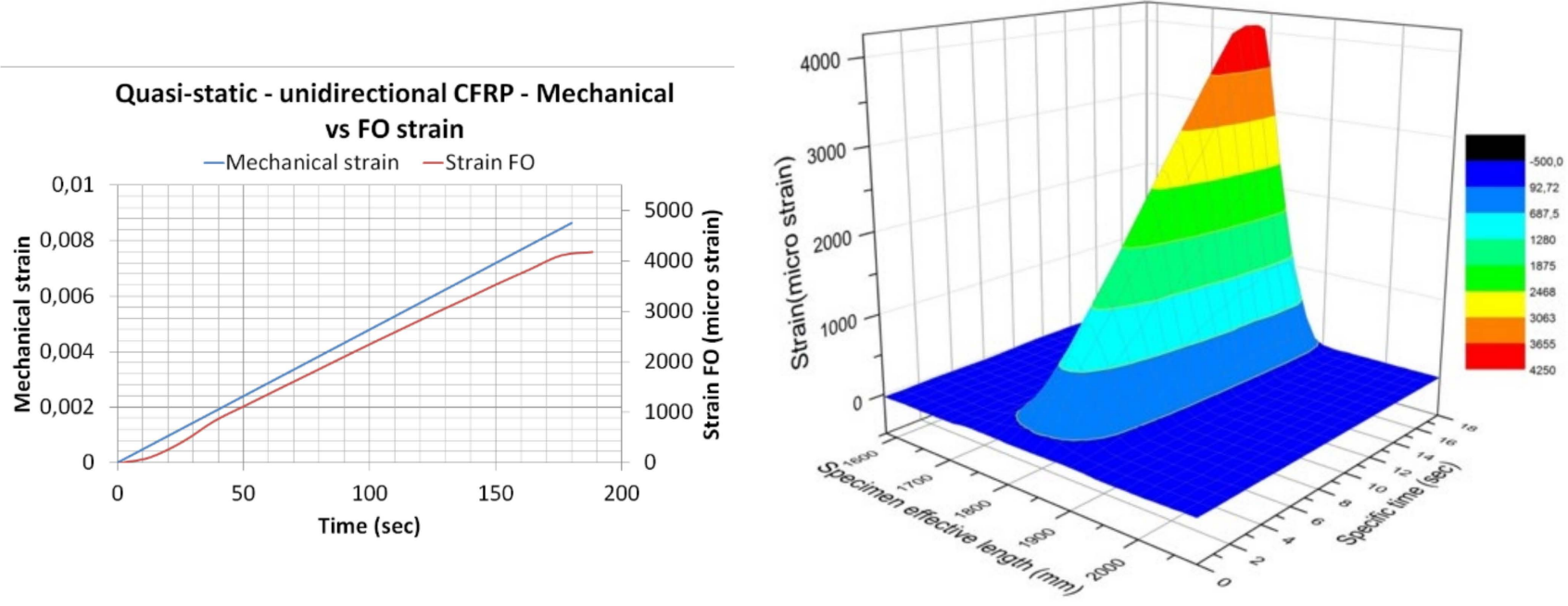

(a)
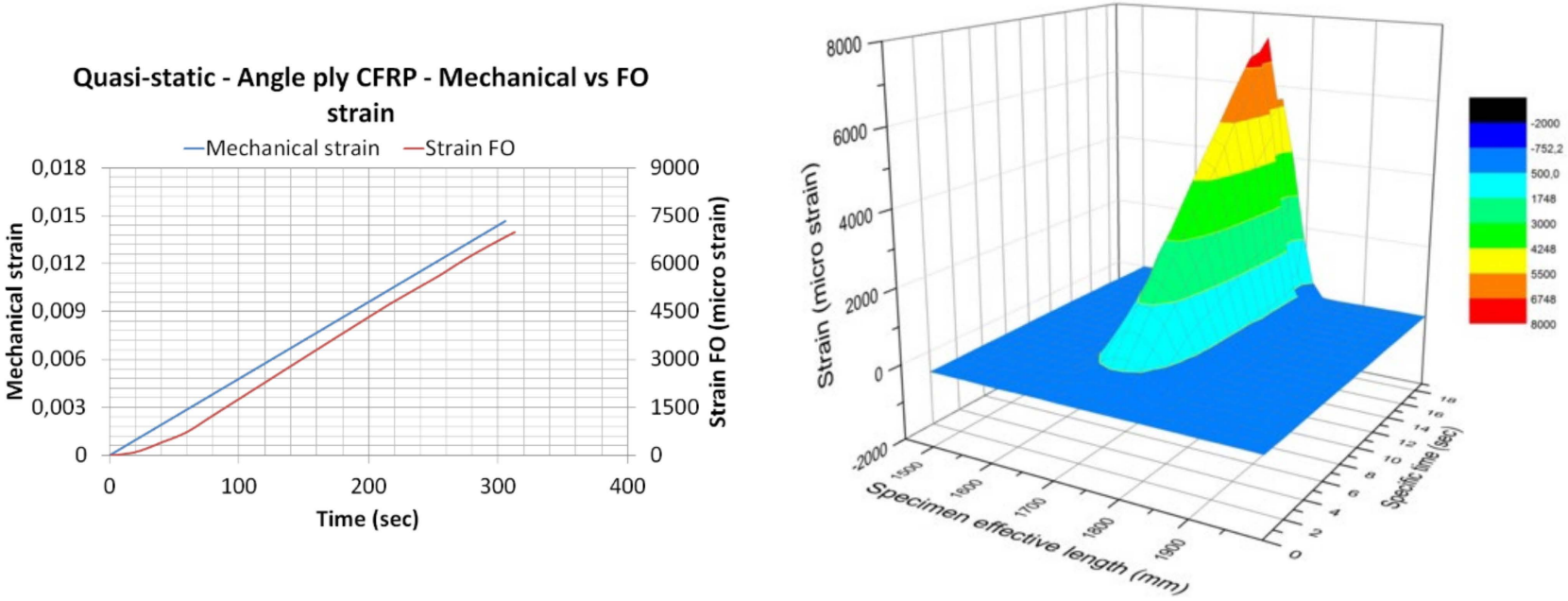

(b)

Figure 17. (a) Quasi-static test curve of UD smart specimen along with the 3-D curve of UD smart specimen. (b) Quasi-static test curve of angle-ply smart specimen along with the 3-D profile curve.

Figure 17b shows a comparative mechanical strain recorded by MTS testing machine and FOS. The maximum strain detected by FOS in UD smart specimen is 4083 micro strain. The 3-D curve is plotted to show whether FOS is sticking to its original position without breaking and/or sliding. It shows bending profile of FOS signals during the whole experiment. If FOS breaks, no signals will appear. Moreover, if FOS slides inside a composite ply, the location of curve will be shifted from its initial position. Therefore, 3-D plot is a complimentary curve to confirm the performance of FOS. It is clearly shown from the 3-D profile curve that same increase is recorded by the two sensors.

In angle-ply specimens, FOS fits the mechanical strain. 3-D profile confirms that FOS finely worked without failure nor sliding. The FOS strain value reaches 7000 microstrain, because angle-ply specimen's mechanical strain (0.0143) is higher than UD specimen's strain (0.0085).

\subsubsection{Load-Unload Test}

Figure 18 shows the load-unload test of a UD smart specimen. The ascending and descending parts of displacement were finely detected by embedded FOS and are shown by red color. The strain range is similar to the strain values observed in quasi-static 
test. Therefore, FOS strain may be used directly without conversion factor. In angle-ply specimens, FOS strain curve reflects the nonlinear behavior of smart composites (Figure 19). Nonlinear strain values increase in each load-unload cycle, which is highlighted by circles in the figure. The mechanical strain does not show nonlinear behavior, because the test was displacement-imposed. Finally, in both experiments, 3-D profile confirms the proper working of FOS, and neither curve shift nor fluctuations are shown.
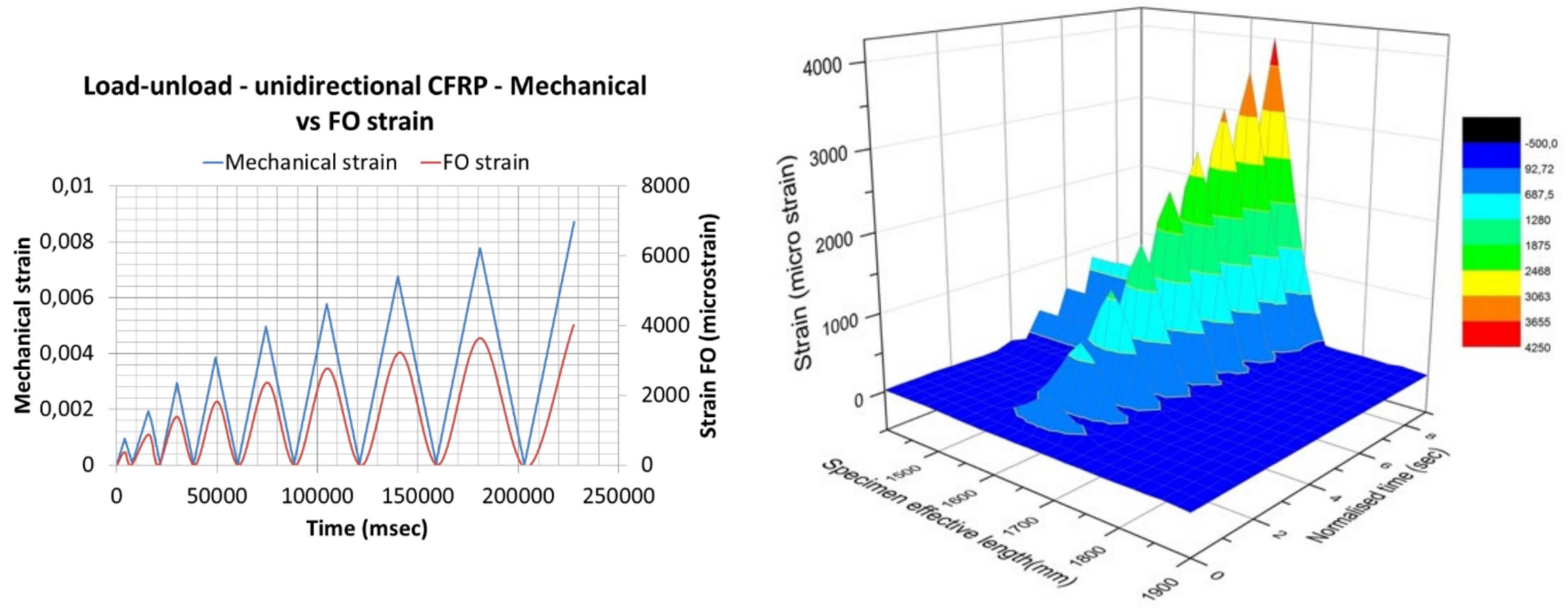

Figure 18. Load-unload test curve for smart UD specimen along with 3-D load-unload test curve.
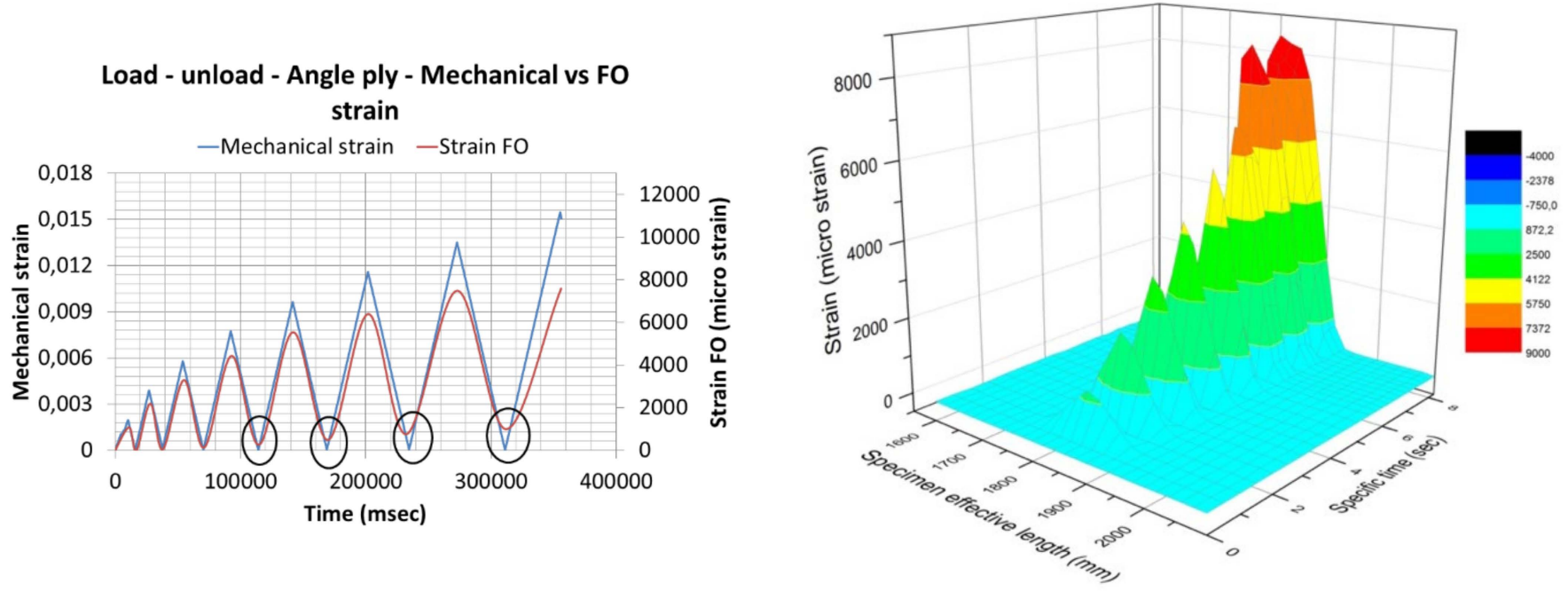

Figure 19. Load-unload test curve for smart angle-ply specimen along with the 3-D load-unload curve.

\subsubsection{Low Number Fatigue Cycles (LNCF) Tests}

This section is proposed to confirm whether FOS signals are coherent and operating throughout the cycles. Initiation of nonlinear strain in material leads to stiffness reduction. Stiffness and FOS strain were analyzed by normalized values. Figure 20a-c show the LCF curves corresponding to $0.6 \sigma \mathrm{p}, 0.8 \sigma \mathrm{p}$, and $1.0 \sigma \mathrm{p}$ loads, respectively. In all tests, FOS provides strain values up to the end of cycling. The 3-D profile also confirms that FOSs are fulfilling their mission without any degradation. 


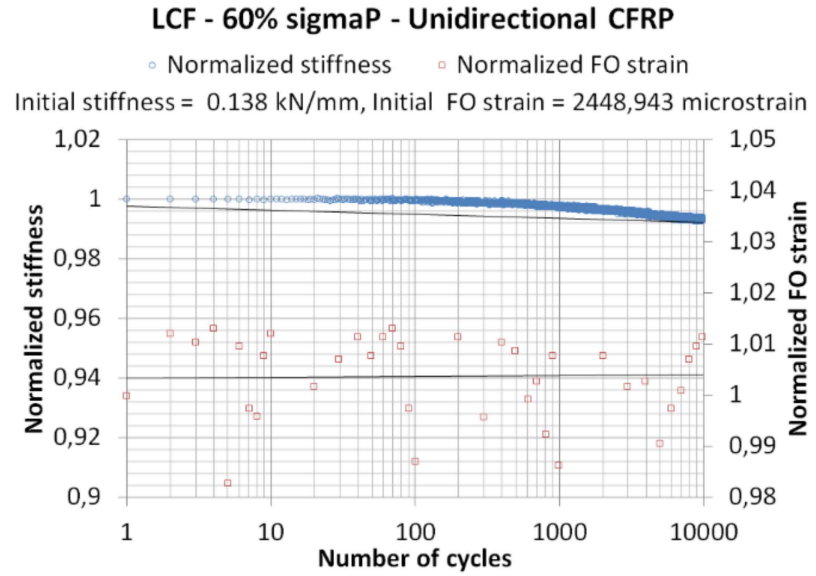

(a)

\section{LCF - $\mathbf{8 0 \%}$ sigmaP - Unidirectional CFRP}

Normalized stiffness $\square$ Normalized FO strain Initial stiffness $=0.1345 \mathrm{kN} / \mathrm{mm}$, Initial FO strain $=2969,1$ micro strain

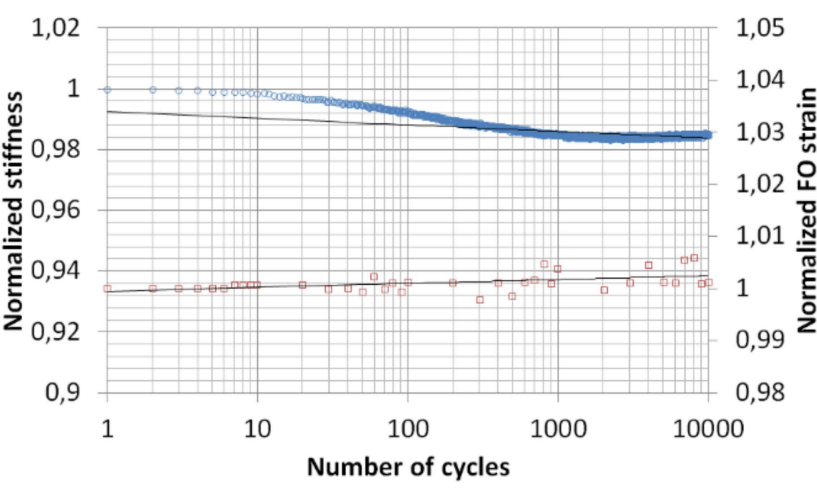

(b)
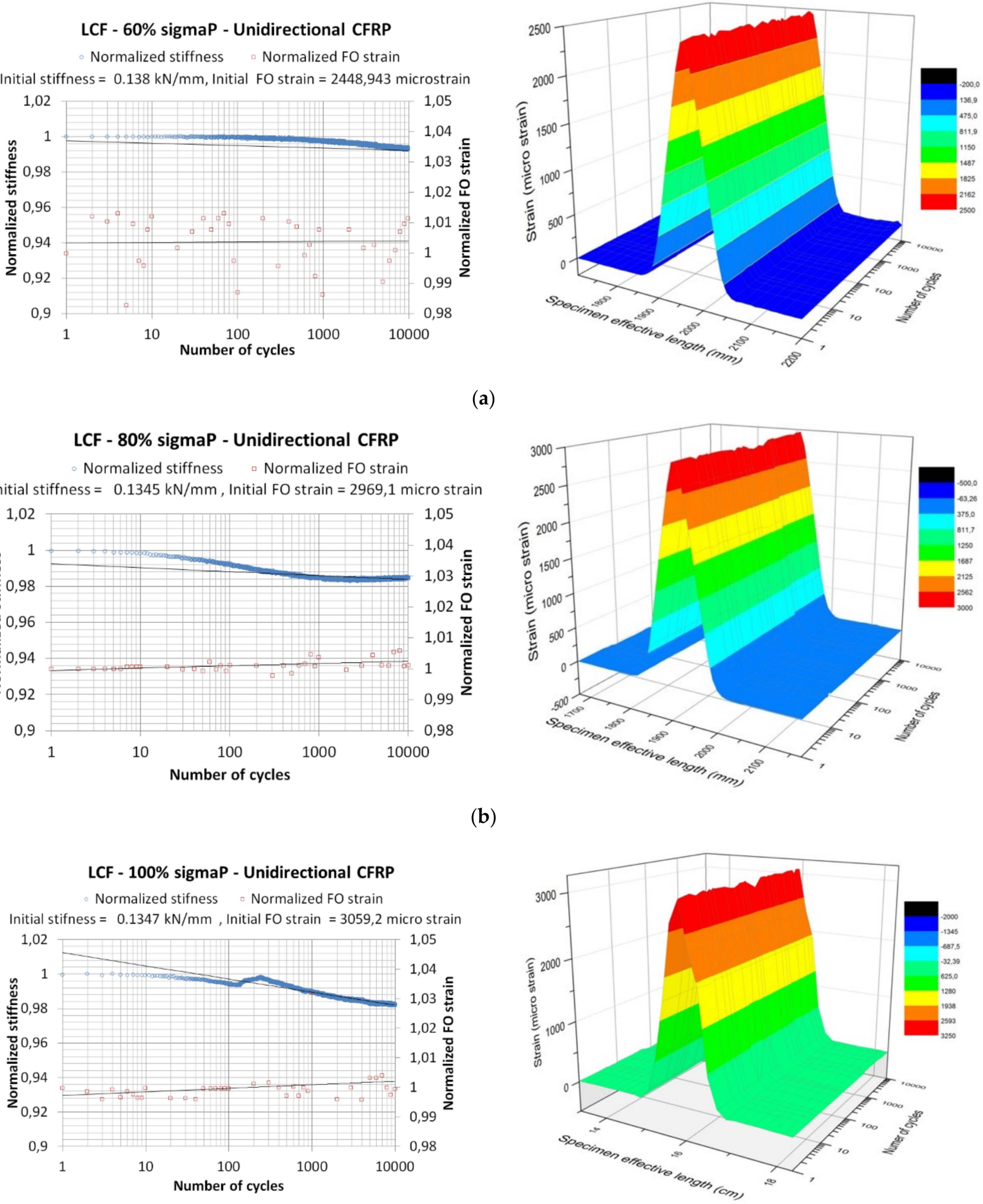

(c)

Figure 20. LCF test and associated 3D profile curves of the (a) $0.6 \sigma p$, (b) $0.8 \sigma p$, and (c) $1.0 \sigma p$ maximum applied stress of UD smart specimen.

In the case of UD specimen loaded at $0.6 \sigma p$, results show constant stiffness and constant FOS strain over all the $10^{4}$ cycles, which indicates that damage is negligible 
(Figure 20). Indeed, in both Y-axes, the values remain constant, which confirms that the stiffness values and FOS strains were maintained in all fatigue test cycles. For fatigue test on UD specimen that was loaded at $0.8 \sigma p$, stiffness drop was estimated as $1.5 \%$. This stiffness drop is coherent with the FOS strain that increased. The stiffness values become stabilized after some number of cycles. Damage such as matrix microcracking, fiber debonding, and delamination are assumed to be at the origin of this stiffness drop. For the case of fatigue test on UD specimen that was loaded at $1.0 \mathrm{\sigma p}$, the curve indicates a significant drop in stiffness up to the end of cycling. The stiffness drop is estimated to be $2 \%$. FOS strain curve shows an ascending profile, which is coherent with stiffness loss. Once again, matrix microcracking, fiber-matrix decohesion, maybe the higher number of carbon fibers failures compared with previous tests, as well as delamination around FOS encapsulation can explain higher stiffness loss.

Fatigue curves of angle-ply specimens corresponding to $0.6 \sigma p, 0.8 \sigma p$, and $1.0 \sigma p$ are depicted in Figure 21; further, in angle-ply specimens, FOS strain is measured for all cycles. Reliable behavior of FOS is shown on 3-D curves throughout fatigue tests. The test carried out at 0.6 op load shows no decrease in stiffness overall, which confirms that damage is negligible. FOS strain values are constant too. On the Y-axis of FOS strain, the values remain close to 1 and there is no variation noted. For the test performed at a maximum stress of $0.8 \sigma p$, stiffness drop is estimated as $2 \%$ and FOS strain values increased too. For the test conducted at a maximum load of $1.0 \mathrm{op}$, the curve indicates a drop in stiffness that was estimated to be $2 \%$. This behavior is confirmed by FOS strain curve that shows a high angle in ascending part. It confirms damage initiation and propagation. It can be noted from what precedes that FOSs are able to record variation of strain during fatigue tests in a reliable way and this is proven by the high coherence between strain values recorded by FOS and the ones recorded by MTS mechanical sensor.

\subsection{High Number Fatigue Cycles (HNFC) Test}

As stated above, one of the targets of current research was also to check for reliability of FOS over $10^{6}$ cycles fatigue test. As the test that was conducted at 0.6 op showed no stiffness loss in LNFC test for both UD and angle-ply smart specimens, this maximum fatigue stress value was used for HNFC experiment. The idea is to check whether the initial stiffness can be kept safe over 1 million cycles, which will help us obtain a snapshot of the performance status of the current smart composite and how reliable it is for possible structural applications. The HNFC test result of UD smart specimen is depicted in Figure 22. No stiffness decrease was recorded up to the end of the test. FOS also detected strains for all cycles, confirmed by the associated 3-D profile curve.

In HNFC test conducted on angle-ply specimens, the stiffness is same for all fatigue test cycles. The FOS records strain up to the end of the test (Figure 23). It confirms that FOS was not damaged during fatigue loading. Once again, 3-D profile curve proves reliable signal recording throughout the experiment. 


\section{LCF - 60\% sigmaP - Angleply CFRP}

Normalized stiffness Normalized FO strain

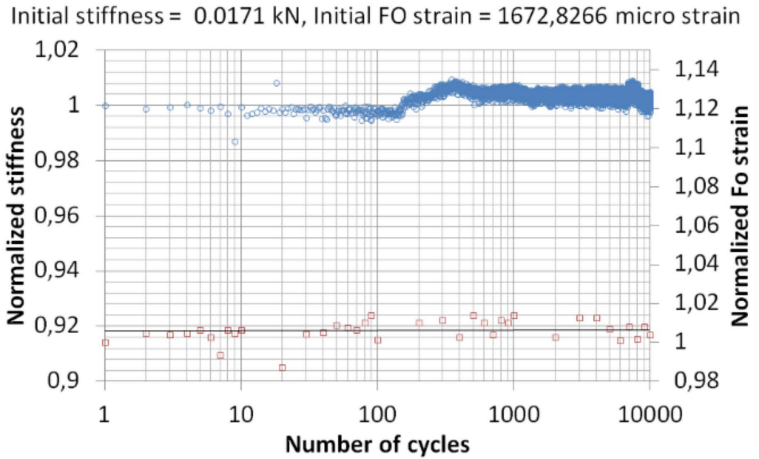

LCF - $\mathbf{8 0 \%}$ sigmaP - Angle ply CFRP

Normalized stiffness $\square$ Normalized FO strain Initial stifness $=0.0171 \mathrm{kN} / \mathrm{mm}$, Initial FO strain $=2635,114$ microstrain

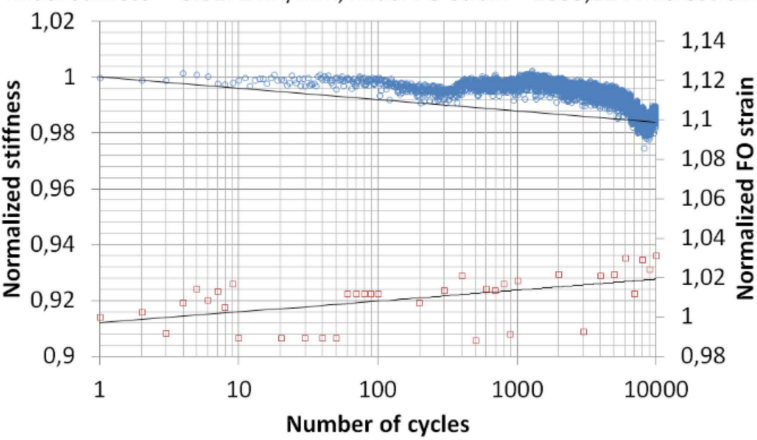

LCF - 100\% sigmaP - Angle ply CFRP

Normalized stiffness Normalized FO strain Initial stiffness $=0.0171 \mathrm{kN} / \mathrm{mm}$, Initial FO strain $=2768,969$ microstrain

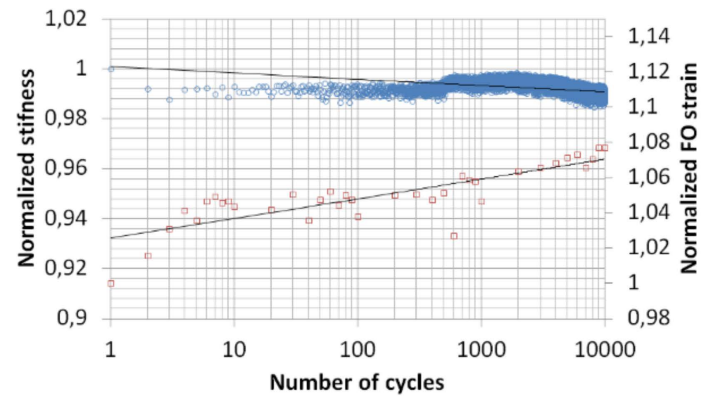

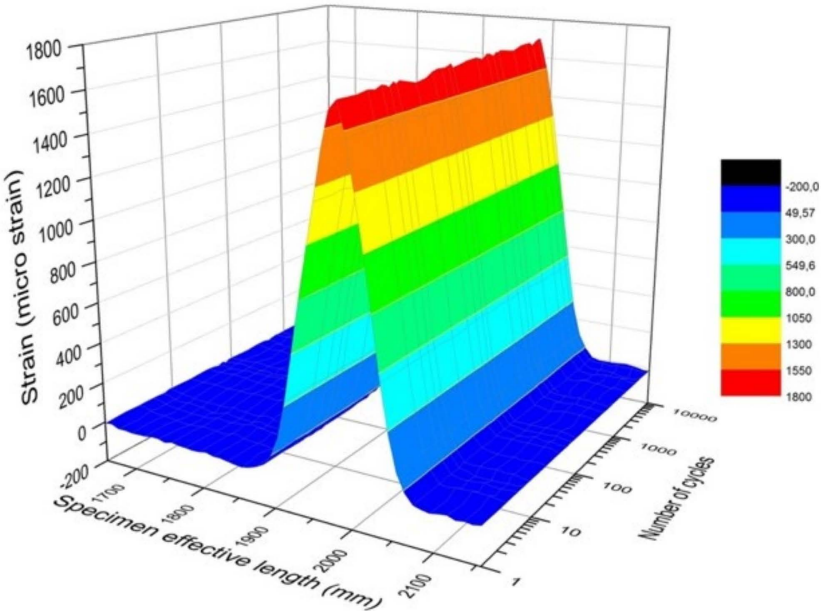
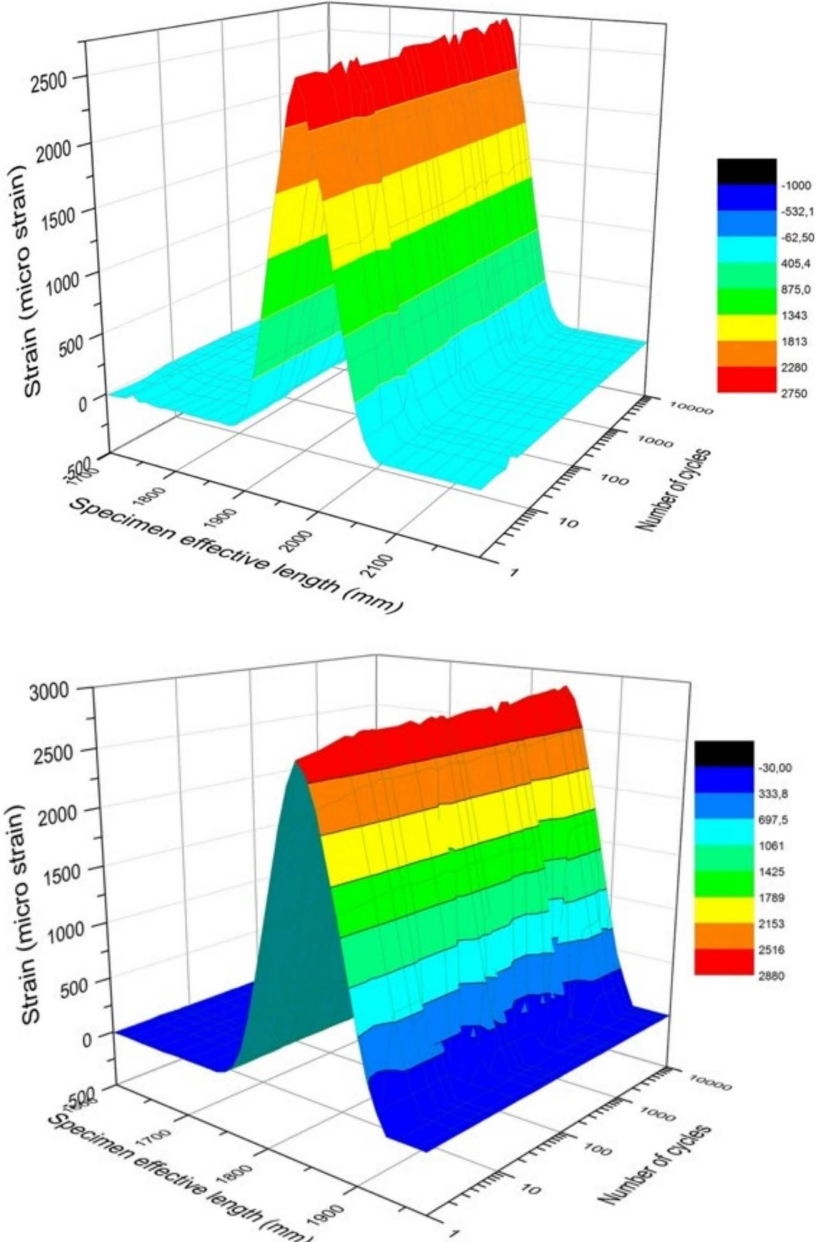

Figure 21. LCF test at a maximum stress of $0.6 \sigma p, 0.8 \sigma p$, and $\sigma p$ of angle-ply smart composite along with 3-D corresponding test curve. 

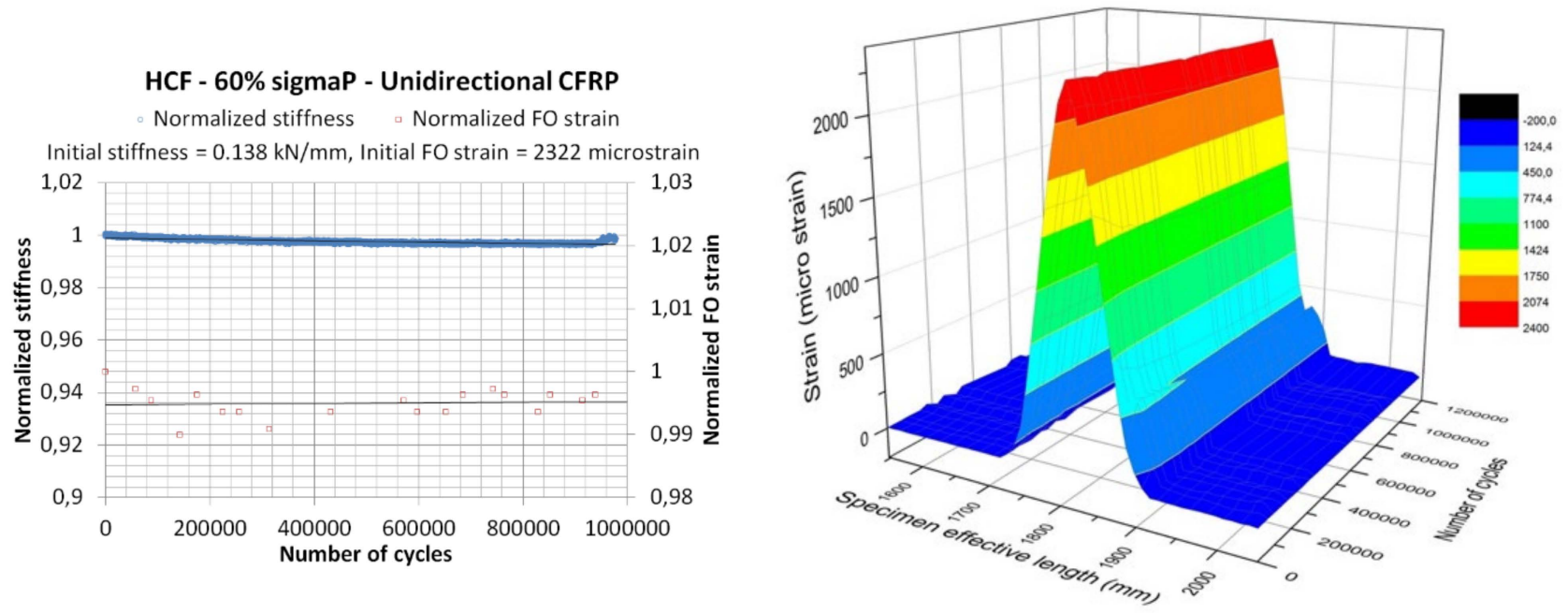

Figure 22. HNCF test curve (0.6 $\sigma p)$ of UD smart specimen and corresponding 3-D HNCF test curve.
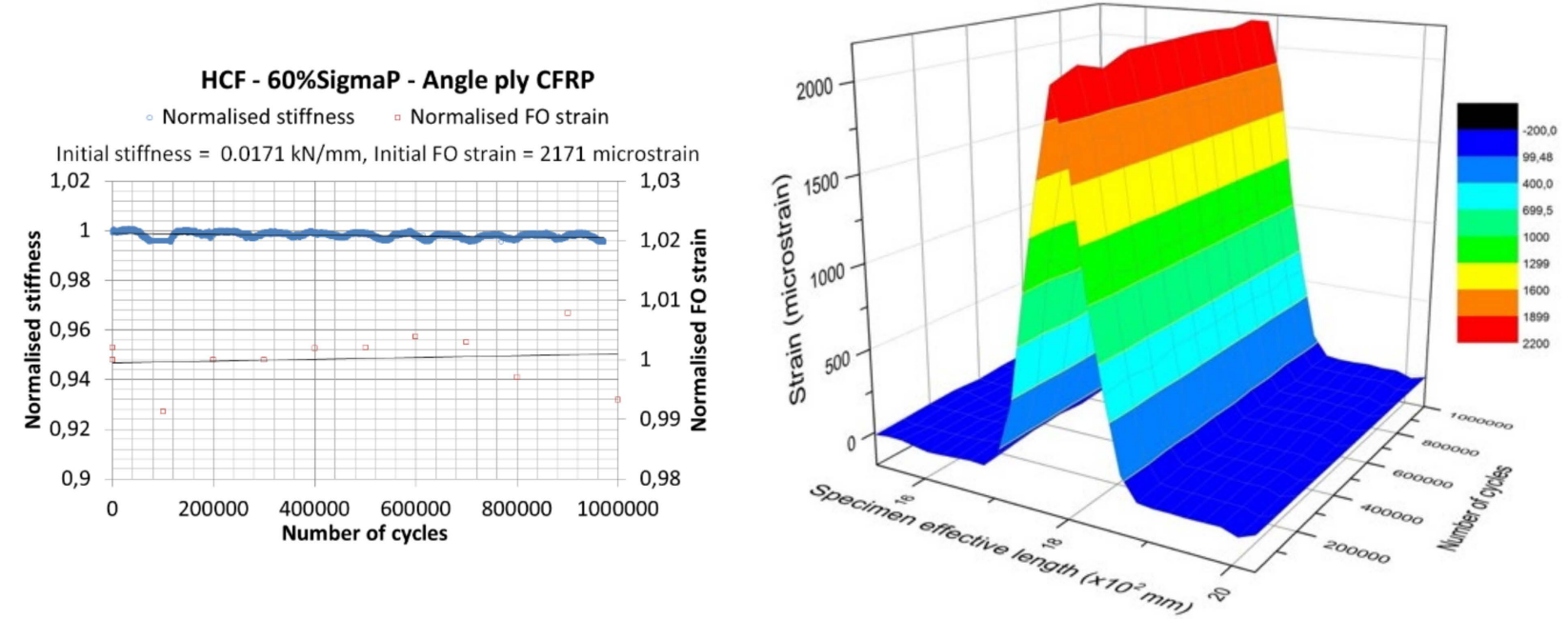

Figure 23. HNCF test curve corresponding to a maximum stress $0.6 \sigma \mathrm{p}$ in angle-ply smart specimen along with corresponding 3-D HCF test curve.

\section{Discussion}

From what precedes, one can conclude that FOS are able to record strain in composite material under high number fatigue cycles test for both UD and angle-ply composites. FOS kept safe its mechanical integrity, as well as its sensing potential. This potential allows them to be reliable embedded sensors for smart composite structures. For the maximum fatigue stress levels studied and up to one million cycles, it is clearly shown that the reliability of the intelligent composite is certainly not related to the mechanical and/or physical performance of optical fiber sensors.

The point that seems crucial to us is related to the damage that arises around the zones where the optical fiber is embedded and to its future and rapid propagation in mode II (Figures 24 and 25) under complex mechanical stresses that may happen in-service. Let us not forget that compared with the parent composite material, the optical fiber sensor is a "flaw", whose harmfulness depends on its size; positioning; and physicochemical, thermal, and physical compatibility with the parent material. Even if the size of the optical fibers were reduced and the physicochemical, physical, and thermal compatibilities were totally controlled, the danger of delamination and propagation in mode II around the sensor would remain. Indeed, it seems to us that certain fibrous reinforcement architectures are not compatible with the insertion of sensors, and this is the case, in particular, with cross-ply composites. 


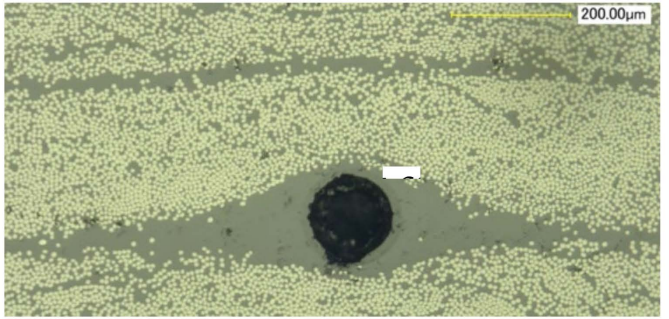

(a)

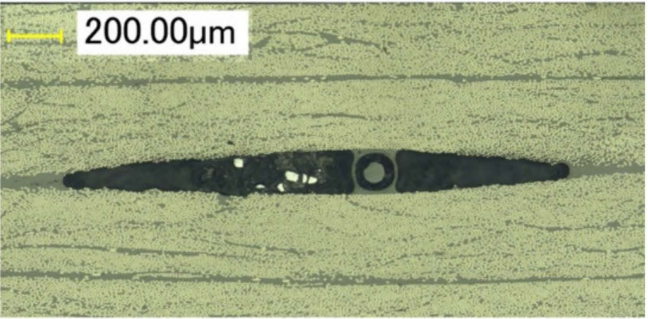

(b)

Figure 24. (a) Cross-section of untested UD smart specimen. (b) Cross-section of untested angle-ply specimen.
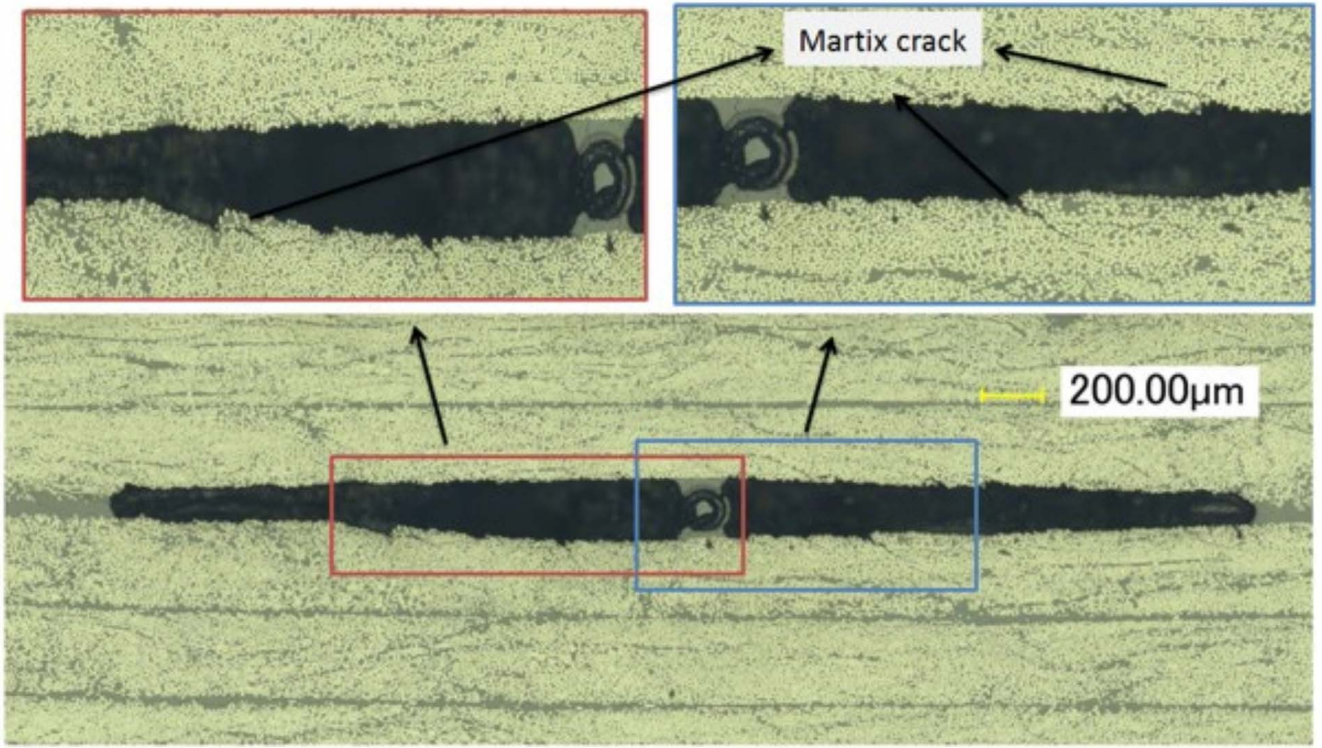

Figure 25. Numerical microscopy analysis for damage in postmortem cross-section-angle-ply specimen with FOS.

\section{Conclusions}

This work showed, through some fatigue experiments under 3-point bending, some encouraging results regarding the effectiveness of embedding FOS in CFRP material. Current mechanical properties of CFRP, while FOS is embedded, have been evaluated. Results showed that there is no detrimental decrease in mechanical properties of the smart composite resulting from embedding FOS. Although, some additional care should be taken when encapsulating FOS to avoid premature delamination. Besides, the smart composite was able to show that embedded FOS performs well and provides significant strain values even after one million cycles, under a maximum stress value of $470 \mathrm{MPa}$ for UD composite and $52 \mathrm{MPa}$ in the case of $\pm 45^{\circ}$-oriented material.

Results also showed that significant progress has to be done in reducing as much as possible the size of resin pocket defects in the interplies areas located around FOS. These defects may strongly promote initiation and propagation of delamination cracks even at a very low stress level, especially in $\pm 45^{\circ}$ composites. Further, it is clear that using embedded optical fiber sensors with cross-ply composites does not come up with a full guarantee of service, since, after all, the embedded optical fiber sensor is and will still remain a "flaw" according to mechanics and materials theory and must absolutely be treated as such from a structural mechanics perspective to avoid any kind of future disillusioned industrial structural application. 


\begin{abstract}
Author Contributions: Conceptualization, methodology, investigation, resources, writing-review and editing, supervision, project administration, funding acquisition, M.D.-H.; software, validation, formal analysis, V.R. All authors have read and agreed to the published version of the manuscript.
\end{abstract}

Funding: This research was funded by General Electric, IRT Jules Verne, \& Europe Technologies.

Data Availability Statement: Data is available.

Acknowledgments: This research was conducted within EVEREST Project. It was funded by General Electric, IRT Jules Verne, \& Europe Technologies. MDH (PI of EVEREST) would like to thank the funders for their Support.

Conflicts of Interest: The authors declare no conflict of interest.

\title{
References
}

1. Drissi-Habti, M.; Raman, V.; Khadour, A.; Timorian, S. Fiber Optic Sensor Embedment Study for Multi-Parameter Strain Sensing. Sensors 2017, 17, 667. [CrossRef] [PubMed]

2. Raman, V.; Drissi-Habti, M. Numerical simulation analysis as a tool to identify areas of weakness in a turbine wind-blade and solutions for their reinforcement. Compos. Part B Eng. 2016, 103, 23-39. [CrossRef]

3. Raman, V.; Drissi-Habti, M.; Limje, P.; Khadour, A. Finer SHM-Coverage of Inter-Plies and Bondings in Smart Composite by Dual Sinusoidal Placed Distributed Optical Fiber Sensors. Sensors 2019, 19, 742. [CrossRef] [PubMed]

4. Raman, V.; Drissi-Habti, M. Numerical simulation of a resistant structural bonding in wind-turbine blade through the use of composite cord stitching. Compos. Part B Eng. 2019, 176, 107094. [CrossRef]

5. Drissi-Habti, M.; el Assami, Y.; Raman, V. Multiscale Toughening of Composites with Carbon Nanotubes-Continuous Multiscale Reinforcement New Concept. J. Compos. Sci. 2021, 5, 135. [CrossRef]

6. Lim, D.-W. Development of Self-Powered Wireless Structural Health Monitoring (SHM) for Wind Turbine Blades. Ph.D. Thesis, University of Minnesota, Minneapolis, MN, USA, 2015.

7. Holnicki-Szulc, J.; Rodellar, J. Smart Structures: Requirements and Potential Applications in Mechanical and Civil Engineering; Nato Science Partnership Subseries: 3; Springer: Berlin/Heidelberg, Germany, 2012.

8. Riccio, A.; DiCaprio, F.; Camerlingo, F.; Scaramuzzino, F.; Gambino, B. Positioning of embedded optical fibres sensors for the monitoring of buckling in sti ened composite panels. Appl. Compos. Mater. 2013, 20, 73-86. [CrossRef]

9. Ansari, F. Structural health monitoring with fiber optic sensors. Front. Mech. Eng. China 2009, 4, 103-110. [CrossRef]

10. Barrias, A.; Casas, J.R.; Villalba, S. A review of distributed optical fiber sensors for civil engineering applications. Sensors 2016, 16, 748. [CrossRef] [PubMed]

11. Fiber Optic Basics. Available online: https://www.newport.com/t/fiber-optic-basics (accessed on 12 October 2016).

12. Dasgupta, A.; Sirkis, J.S. Importance of coatings to optical fiber sensors embedded in 'smart' structures. AIAA J. 1992, 30, 1337-1343. [CrossRef]

13. Barton, E.; Ogin, S.; Thorne, A.; Reed, G. Optimisation of the coating of a fibre optical sensor embedded in a cross-ply GFRP laminate. Compos. Part A Appl. Sci. Manuf. 2002, 33, 27-34. [CrossRef]

14. Pradhan, H.S.; Sahu, P.K. A survey on the performances of distributed fiber-optic sensors. In Proceedings of the 2015 International Conference on Microwave, Optical and Communication Engineering (ICMOCE), Bhubaneswar, India, 18-20 December 2015; pp. 243-246.

15. Alfredo, G.; Antonio, F.-L.; Lozano, A. Fiber Optic Distributed Sensing NATO STO, STO-EN-AVT-220. 2014. Available online: https://www.sto.nato.int/publications/STO\%20Educational\%20Notes/STO-EN-AVT-220/EN-AVT-220-04.pdf (accessed on 25 November 2021).

16. Abhisek, U.; Hubert, B.; Peter, K. Distributed Temperature Sensing: Review of Technology and Applications. IEEE Sens. J. 2012, 12, 885-892. [CrossRef]

17. OBR 4600 J Luna. Available online: http:/ / lunainc.com/obr4600 (accessed on 7 March 2017).

18. Grattan, K.; Sun, T. Fiber optic sensor technology: An overview. Sens. Actuators A Phys. 2000, 82, 40-61. [CrossRef]

19. Drissi-Habti, M. EVEREST Project Report; Internal Technical Report; EVEREST: Nantes, France, March 2014.

20. Standard Test Methods for Flexural Properties of Unreinforced and Reinforced Plastics and Electrical Insulating Materials-ASTM D790, Standard; ASTM International: West Conshohocken, PA, USA, 2002.

21. Rajan, G. Optical Fiber Sensors: Advanced Techniques and Applications, Devices, Circuits, and Systems; CRC Press: Boca Raton, FL, USA, 2015.

22. Drissi-Habti, M. Damage development and moduli reduction in a unidirectional SiC-MAS.L composite tested under uniaxial tensile loading. Scr. Metall. Mater. 1995, 33, 967-973. [CrossRef]

23. Drissi-Habti, M. Mechanical Behavior of Large Size Compact Tension Specimens of 2D Woven SiC-SiC Composite Materials. In Fracture Mechanics of Ceramics; Bradt, R.C., Hasselman, D.P.H., Munz, D., Sakai, M., Shevchenko, V.Y., Eds.; Springer: Boston, MA, USA, 1996; Volume 12. [CrossRef]

24. Drissi-Habti, M. Etude de L'endommagement en Traction Uniaxiale des Composites SiC-MAS.L. Sil. Ind. 1996, 61, 191-200.

25. Drissi-Habti, M. Assessment of the mechanical behaviour of the SiC fibre reinforced magnesium lithium aluminosilicate glassceramic matrix composite tested under uniaxial tensile loading. J. Eur. Ceram. Soc. 1997, 17, 33-39. [CrossRef] 
26. Drissi-Habti, M.; Nakano, K. Microstructure and mechanical behavior of the Hi-Nicalon fiber reinforced-silicon nitride composite material. Compos. Sci. Technol. 1997, 57, 1483-1489. [CrossRef]

27. Drissi-Habti, M.; Nakano, K. Local mechanical characterisation and interfacial behaviour in Hi-Nicalon/ $/ \mathrm{BN}^{-}-\mathrm{Si}_{3} \mathrm{~N}_{4}$ ceramic matrix composites. J. Eur. Ceram. Soc. 1998, 18, 1845-1855. [CrossRef]

28. O'Brian, T. Long-term Behavior of Composites. In ASTM Special Technical Publication; ASTM: West Conshehoken, PA, USA, 1983.

29. Creed, R.F., Jr. High Cycle Tensile Fatigue of Unidirectional Fiber Glass Composite Tested at High Frequency. Master's Thesis, Montana State University, Bozeman, MT, USA, 1993.

30. Wen, J.; Xia, Z.; Choy, F. Damage detection of carbon fiber reinforced polymer composites via electrical resistance measurement. Compos. Part B Eng. 2011, 42, 77-86. [CrossRef]

31. Corten, H. Composite Materials: Testing and Design (Second Conference). In Proceedings of the ASTM International: Selected Technical Papers, Anaheim, CA, USA, 20-22 April 1971; ASTM International: West Conshehoken, PA, USA, 1972.

32. Jang, T.S.; Lee, J.J.; Lee, D.C.; Huh, J.-S. The mechanical behavior of optical fiber sensor embedded within the composite laminate. J. Mater. Sci. 1999, 34, 5853-5860. [CrossRef]

33. Boyer, H.; Metals, A. Atlas of Fatigue Curves; American Society for Metals: Almelle, The Netherlands, 1985.

34. Ashcroft, A. Fatigue load conditions. In Handbook of Adhesion Technology; da Silva, L.F.M., Fichsner, A., Adams, R.D., Eds.; Springer: Berlin/Heidelberg, Germany, 2011; pp. 84-874. [CrossRef] 